\title{
الاستدلال الكمي لدى طابة المرحلة المتوسطة
}

م.د. حامد شياع ضير الله / جامعة القادسبية

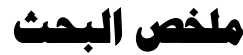

$$
\begin{aligned}
& \text { لا تتجح عملية تعليم وتعلم الرياضيات دون عمل يو ازي بين استيعاب المفاهيم والحقائق العددية من جهة؛ و المعادلات و العمليات من جهة }
\end{aligned}
$$

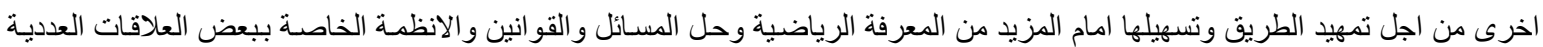

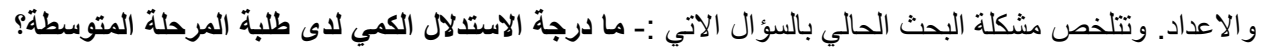

$$
\begin{aligned}
& \text { وتأتي اهمية الاستدلال الكمي من حيث لا تتحقق من خلال طرق التدريس التقليدية او عن طريق الحفظ الاستظهاري والتركيز المبالغ } \\
& \text { فيه، ولهذا فأن الاستدلال الكمي ذو اهيـة في تحديد وثائق تربويات الرياضيات المعاصرة لآنه يجسد الخصـائص الاولية لتعلم الرياضيات }
\end{aligned}
$$

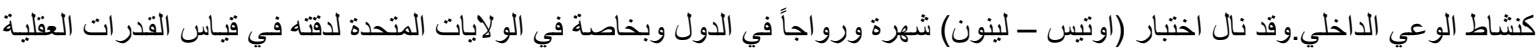

$$
\begin{aligned}
& \text { وتضمنه عدداً من الاسئلة الخاصة لقياس الاستدلال الكمي. } \\
& \text { هدف البحث الى الكثف عن درجة الاستدلال الكمي لطلبة المرحلة المتوسطة، ومعرفة الفروق في الاستدلال الكمي بين الذكور والاناث }
\end{aligned}
$$

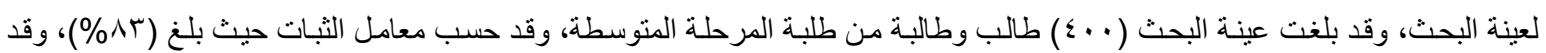

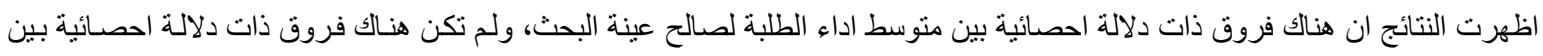

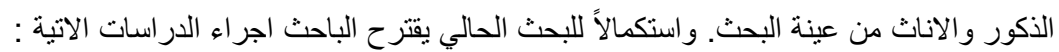

$$
\begin{aligned}
& \text { 1 - الاستدلال الكمي في كتب الرياضيات المرحلة المتوسطة. }
\end{aligned}
$$

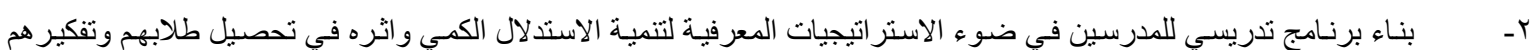

$$
\begin{aligned}
& \text { الاستدلالي. }
\end{aligned}
$$

\section{Abstract}

Do not succeed the process of education and learn mathematics without the work of balance between absorb the concepts and facts numerical on the one hand; and skills and processes of the other hand, in order to pave the way and facilitate in front of more mathematical knowledge and problem solving and laws and regulation for some of the relation numerical and preparation are summarized the main problem current following question :-

\section{What's degree of inference quantitative the student of the intermediate stage?}

The importance of inference quantitative where do not be achieved through the teaching method traditional to study ways to conservation (memorization) and focus exaggerated, therefore be inferred quantitative importance in determining the document educational mathematics and contemporary because if embodies the characteristics of the initial to learn mathematics as an activity consciousness internal.

Has won the test (Otes - Lennon) fame and popular in the countries and success in the United states of accuracy in the measurement of mental abilities include a number of questions to measure the inference quantitative goal of search to detect degree of inference quantitative student of the intermediate stage and find out the difference in the inference quantitative between (male and female) sample search amounted to research sample (400) students of the intermediate stage where according to reliability reaching (83\%).

The results showed there are statistically significant difference between the average student performance for research sample.

There were so statistically significant difference between male and female in the research sample.

To complement to search the current suggest the researches conducting the following studies :-

1- Inferred quantitative in the books mathematics the intermediate stage.

2- Building program teaching teachers in the light of the strategic cognitive development to inference quantitative and its impact in the collection of their students and thinking inferential. 


\section{الفصل الاول : التعريف بالبمث}

مشكلة البحث :

شهدت مناهج البحث في النصف الثاني من القرن العشرين موجات متلاحقة من التغيير والتطور السريع، وبالر غم من ذلك بقيت الاعداد وعملياتها الحسابية مركزاً ثنابتاً تدور في فلكه معظم المواضيع الرياضية، وتبقى الاعداد و عملياتها الجو هر و المعنى للرياضيات بجميع فروعها. و لا تتجح عملية تعليم وتعلم الرياضيات دون عمل يوازن بين استيعاب المفاهيم والحقائق العددية من جهة، و المهار ات و العمليات من جهة اخرى من اجل تمهيد الطريق وتسهيلها امام المزيد من المعرفة الرياضية، وحل المسائل. وييرز دور الطالب في اظهار الفهم والاستيعاب من خـلال القدرة الكتلية الرياضية على فهم الاعداد واجر اء العمليات عليها، بحيث يكون قادراً على فهم النظام العددي، ومعرفة الاسس التي تبنى عليها العمليات الحسابية، والقدرة على تقدير الاعداد

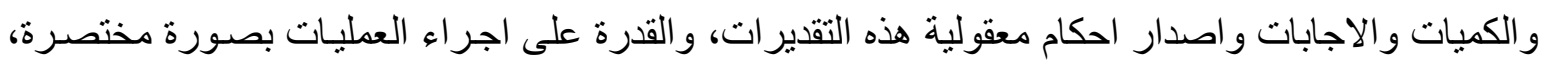
وكذللك القدرة على الاجابـة عن طريـق الحسـاب الذهني، و التمكن مـن الاعداد الكبيرة وفهم المصطلحات الحسابية الاساسية.

ان مفهوم الاعداد اذا لم يقلم بصورة ناجحة يصبح معقداً وغير سهل على الطلبة، وذلك لان الاعداد لها تمثيلات، وصورة، ووجوه عدة، لذلك فأن فهم الاعداد لا يشمل فقط إدر الك العدد، بل يتعداه ليشمل النظام المعقد للعلاقات المنشابكة مثل علاقة اكبر من، اصغر من، وعلاقة الجزء بالكل، و القو انين و الانظمـة الخاصـة ببعض العلاقات العددية و الاعداد، اما الحاجة الى الربط بين الاعداد وكميات حقيقة في البيئة، وعمل قياسـات في البيئة عن طريق الاعداد فهي قضية ليست سـلة ولكنها اساسية يتم تيسير ها بتتميـة الحس العددي لدى

\section{اهمية البمث :}

الاستلال الكمي مفهوم اكدت على اهمية المنظمات المهنية المتعلقة بتربويات الرياضيات، اذ هو المعيار السادس من وثيقة معايير التقويم والمنهج للرياضيات المدرسية التي صدرت عن المجلس القومي الامريكي لعلمي الرياضيات في عام (919(1))، وجاء في هذا المعيار ان من الضروري ان تبنى منـاهج الرياضيات في

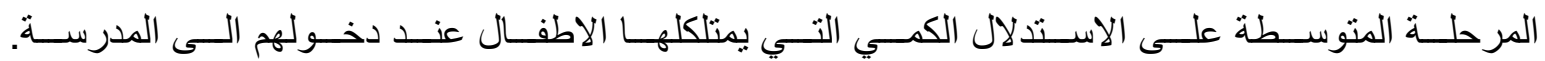

(NCTM, 1989)

كما جاء في وثائق NCTM ان من الاهداف العامة لتدريسي الرياضيات للمتعلمين تتمثل في :

$$
\begin{aligned}
& \text { ا - ان ينتفع المتعلم في قدرته على التعامل بالرياضيات. } \\
& \text { r- ان يحل المتعلم المشكلات الرياضية. } \\
& \text { r- ان يتو اصل المتعلم مع الرياضيات. } \\
& \text { ع- ان يفكر المتعلم بطريقة رياضية. }
\end{aligned}
$$

وكمـا يتضـح من خـلال المعايير التي حددها المجلس القومي لمعلمي الرياضيات في الولايـات المتحدة

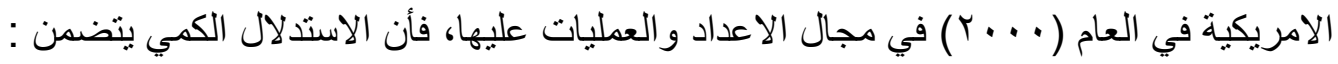


ا - هم الاعداد وطرق تمثيلها والعلاقات فيما بينها و الانظمة العددية.

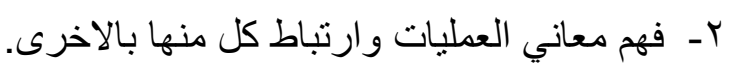
r- المهارة في الحساب واجر اء تقديرات معقولة.

و لا يمكن تحقيق هذه المعايير عن طريق التدريس التقليدي، اي عن طرق الحفظ الاستظهاري والتركيز

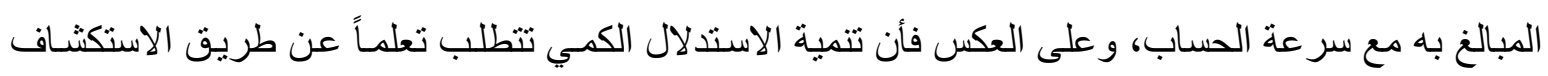

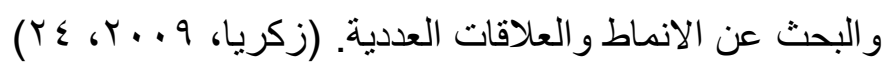

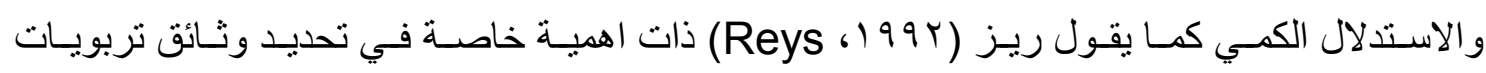

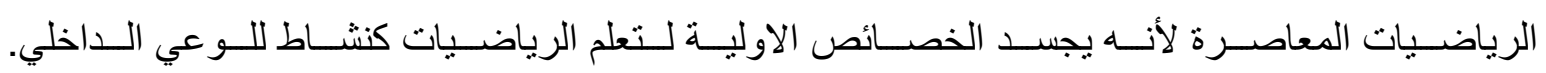
(Reys, 1992, 123) و الاستدلال الكمي كما يقول سـادور (Sowder, 1992) شبكة مفاهيمية منظمـة بطريقة جيدة نمكن الفرد من الربط بين العدد وخو اص العمليات كما تمكنه من حل مسـائل العدد بطريقة مرنسة وابداعية. (Sowder, 1992, 36)

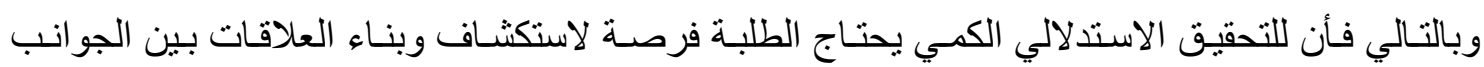
الثثلاث المكونة للنظام الرياضي وهي : الكميات الموجودة فعلياً في الوقت والمكان، والارقام، الرموز الرسمية

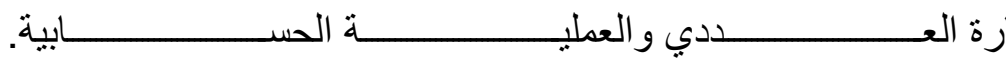

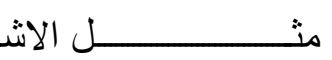

(Griffin, 1997, 14)

ولقد نشطت حركة تطوير وبنـاء وتقنين اختبار (اونيس - لينون) للقدرة العقليـة على البيئة الامريكية

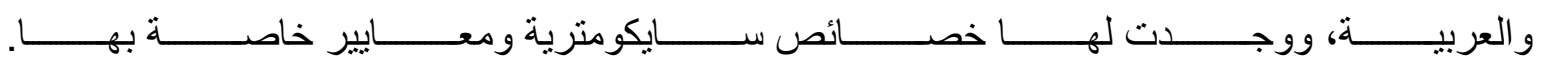

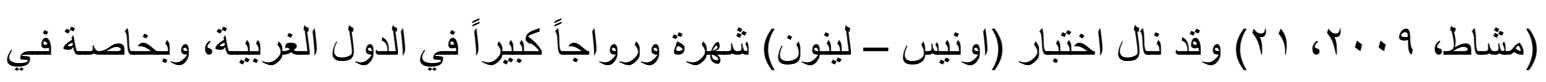

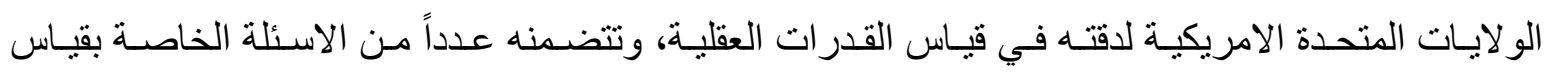

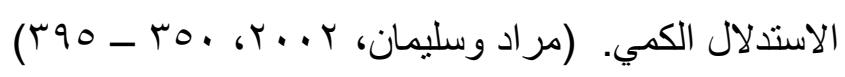
وقد اهتم كثير من الباحث في السنوات الاخيرة بالاستدلال الكمي واجريت عدة درجات حولـه، منها مـا لاحسات اهتم بتنمية الاستدلال الكمي لدى الاطفال من ذوي الاحتياجات الخاصة والاطفال الذين لديهم صعوبات تعلم.

(Gresten \& Chard, 1999 - Licdtke, 1998, Vace, 1995) كما تناولت بعض هذه الدر اسـات علاقة الاستدلال الكمي بتحصيل بعض الموضوعات الرياضية مثنل النسبة المئوية (Gay \& Aicnele, 1997, 185) ودراسات تناولت علاقة الاستدلال الكمي ببعض المتغير ات كالاداء الحسابي الحاب والحساب العقلي. (Trafton, 1998, Reys \& Yand \& Hartoman, 1997) و القدرة على التقدير (Pick \& Forrestor, 1997) واستخدام التكنولوجيا (Calvert, 1999) وحل المسائل (Wickett, 1994) ومنها مـا اهتم بتنشئة وتنميـة الاستدلال الكمي للدى المتعلمين من مستويات 
ان الاطلاع على الادبيات التربوية العربية المنشورة يشير الى قدرة ما يتعلق منها بالاستدلال الكمي ممـا يدعو الى اجر اء مزيد من الدراسات العربية عن الاستدلال الكمي وبذلك يتجلى اهمية البحث الحالي بما يأتي:

$$
\text { 1 - محاولة لسد النقص في الادب التربوي والنفسي المتعلق بالاستدلال الكمي. }
$$

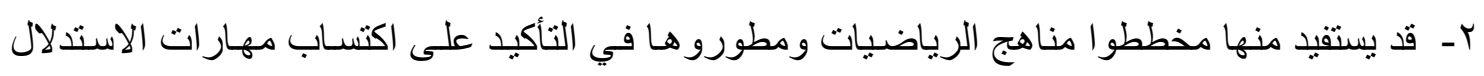

$$
\text { الكمي، كهدف من اهداف تدريس الرياضيات في مر احل التعليم العام. }
$$

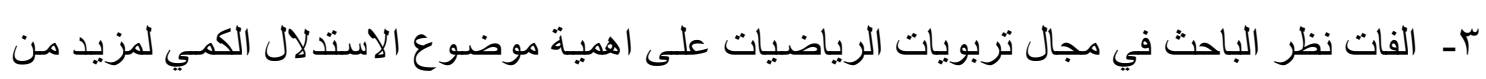

$$
\text { البحث و الدر اسة حوله. }
$$

فرضيات البمش:

لتحقيق اهداف البحث و الاجابة على تساؤلاته تمت صياغة الفرضيات الصفرية التالية :1 - لايوجد فرق ذو دلالة إحصائية عند مستوى دلالة (0 . . ) بين المتوسط الفرضي و المتوسط الحسابي

$$
\begin{aligned}
& \text { لدرجات طلبة عينة البحث في إختبار (اوتيس - لينون) } \\
& H_{0}=\bar{X}_{0}=\bar{X}_{1}
\end{aligned}
$$

r- ل لا يوجد فرق ذو دلالة إحصائية عند مستوى دلالة (0 . . ) بين متوسط درجات طلبة عينـة البحث في

$$
\begin{aligned}
& \text { إختبار (اوتيس - لينون) يعزى لمتغير الجنس (ذكور - اناث) } \\
& H_{0}=\bar{X}_{0}=\bar{X}_{1} \\
& \text { حدود البحث : }
\end{aligned}
$$

يقتصر البحث الحالي على طلبة المرحلة المتوسطة في مدارس المتوسطة والثانويـة الحكوميـة النهاريـة التابعـة

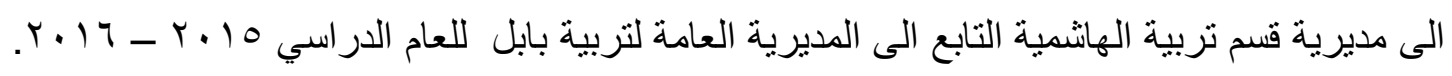

\section{اهداف البحث : يهدف البمث الى : البم}

1- الكثف عن درجة الاستدلال الكمي لطلبة المرحلة المتوسطة.

r- معرفة الفرق في الاستدلال الكمي بين (الذكور ـ الاناث) طلبة المرحلة المتوسطة.

$$
\text { تمديد الامسطمات : الاستدلال الكمي // عرفه : }
$$

ا- جرينو (Greeno, 1991) : عبارة عن تفكير مفاهيمي او استدلالي مفاهيمي يشتمل على المرونة

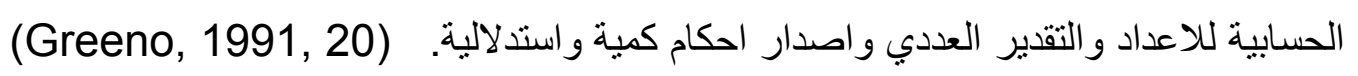
r - رييز (Reys, 1992) : هو احساس الانسـان بخصـائص الاعداد و العمليات عليها ومعناهـا وفهم كيف ومتسى ولمـاذا نستعملها، فكما ان اسلوب حل المشكلات يُعد الاسـاس في الرياضيات بشكل عام فأن

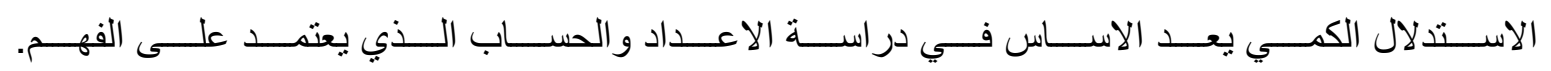

(Reys, 1992, 38) 
ץ- - الطريري (الطريري، ج999 19) : مجموعة النشاط العقلي التي تتمركز وتتمحور حول الانشطة العقلية

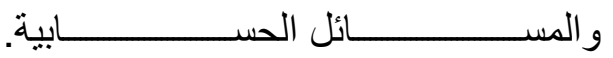
داد والارق لة بالاعـ ذات العلاق

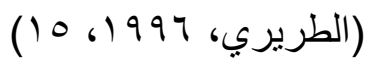

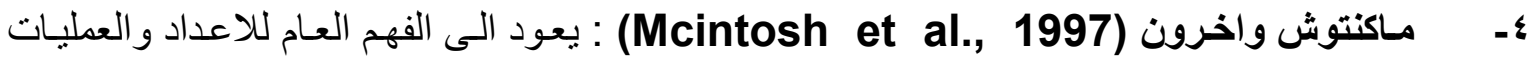
ويثــل ذلك الميلـ والقدرة في استخدام هذا الفهم بطـرق مرنـة مـن اجل اصـدار احكـام رياضية وتطوير استر اتيجيات مفيدة وفعالة في معالجة الاعداد والعمليات، كما يثمل انطباعات الشخص عن الاستدلال الكمي و ان الاعداد عبـارة عـن شـيء لـه وجـود وان الاعـداد مفيدة وان الرياضـيات هـي تفكير مـنظم ومنطقي.

(Mcintosh et al., 1997, 27) - التعريف النظري : سيعتمد الباحثنان في البحث الحالي على تعريف الطريري (997 (1) لأنـه اقرب التعريفات للاستدلال الكمي التي ورد قياسها في اختبار (اونس - لينون). - التعريف الاجرائسي : الدرجـة التي يحصل عليها المفحوص في الاختبـار المستخدم في هذا البحث لقياس الاستدلال الكمي.

\section{الفمل الثاني : الفظفية النظرية ودراسات سابقة}

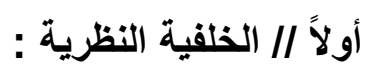

منذ بداية تاريخ القياس العقلي، اهنم علمـاء النفس بمقاييس القدرة العامـة للتعامل مـع الافكار و العلاقات بينها، ومع ان هذا الاهتمام قد نشط جزء منـه بدافع علمي لوصف النشاط العقلي ومهمته، الا ان جزءاً منـه جاء تلبية لحاجات علمية تستهدف التعرف على الاطفال الذين لديهم نقص في الوظيفة العقلية من عليهم ان يتقدموا بشكل طبيعي مع سلم التعلم المدرسي، او على مستوى اكثر حدة التعرف على الافر اد الذين يواجهون

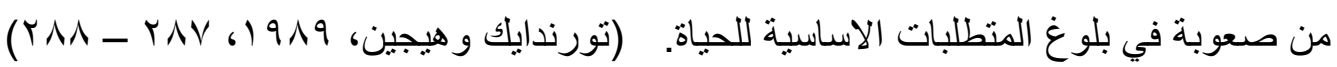
وكان يشـار الـى الاختبار ات المصممة لتقويم الوظـائف العقليـة العامـة في مختلف انواع النشـاط العقلي باختبار ات الذكاء، او الاختبار ات التي تقيس نسبة الذكاء لمـا قد يحمله هذا المصطلح من فائض في المعنى

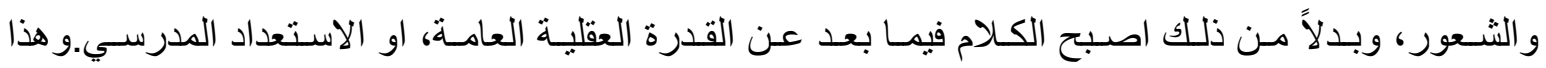
المصطلح الاخير ييرز بشكل خاص وظيفة هذه الاختبار ات كعوامل تثتبأ بـالاداء المدرسي، ايـا كان الاتجاه، فأن الكثير من الثـواهد تدل على ان مدى واسـعاً من المهــات التي تعتمد على مخزون الفرد من الافكار وقدرته على التعامل مع العلاقات بين الافكار تتجمع حول بعضـها البعض وتكوين قدرة عامـة من الفاعلية العقلية، وهذه القدرة تؤثر على الاداء في مدى واسـع من المو اقف الاختياريـة والتي لها دلالاتها في مجال العمل المدرسي، وفي مجالات الحياة الواسعة. (Edward, 1971, 91) وقد ادى نجاح القياس العقلي وانتشاره الى الافادة منه في الميدان التعليمي والمهني و الصناعي ولهذا نشط العاملون بعلم النفس في قياسهم الذكاء للموظفين ثم سعوا الى قياس الخصائص العقلية اللازمـة للنجاح في كل مهنة من المهن المختلفة التي يقوم عليها بنـاء المجتمع الحديث. وقد ادرك الرواد لهذا الاتجـاه الجديد اهمية تحليل المميزات العقلية لكل مهنة من المهن، ولذا يعتمد هذا النوع من القياس على الخطوط العلمية الاتية : 
1- - تحليل العمليات الاساسية للمهنة او الدراسة.

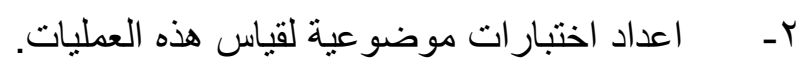

r- در اسة مدى صدق هذه الاختبارات في قياسها لتلك العمليات، وذللك بعد تطبيقها على عدد كبير من هن الافر اد، و الكثف عن صدق هذه الاختبار ات تقديراً لمسنويات هؤلاء الافر اد ويدل على ذلك انتاجهم في

الاعمال التي يقومون بها.

ع-الاستعانة بتلك الاختبار ات مـع اختيار اصلح الافر اد لكل مهنـة وكل دراسـة ابي انها في ذلك تقيس

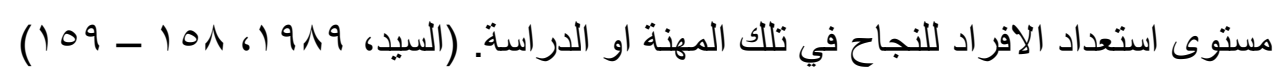
ان اختبار ات الذكاء كانت تقيس اساساً القدرة اللفظية و الى حد مـا تحـاول ان تقبس القدرة العدديـة وبعض القدرات الاخرى المتعلقة بالقدرة على التجريد واستخدام الرموز ـ. لذلك بدأ العلمـاء يعيدون النظر في اصـلاح اختبار ات الاستعداد العددي Scholatic Aptitude وذلك لادر اكهم ان هذه الاختبار ات انمـا تقيس مجمو عـة مـن القـدرات التـي يتطلبهـا النجـاح الدر اســي سـواء الثقافـات الغربيـة، او الثقافـات الاخـرى المماتلــة لهــا.

(Henerson, 1978, 88 - 89)

وقد ادرك العلماء حاجتهم لاختبار ات تقيس الاستعدادات ثم استخدم هذه الاختبار ات في مجالات الاختبار المهني، والتوجيه المهني، وفي المجالات العسكرية ومن اكثر اختبار ات الاستعدادات الخاصـة استخداماً هي اختبار ات الاستعدادات الميكانيكية، واختبار ات الاستعدادات الكتابية، واختبار ات الاستعدادات الموسيقية. كذلك

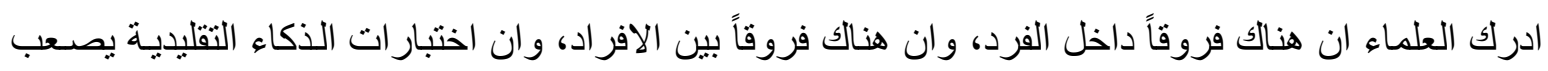

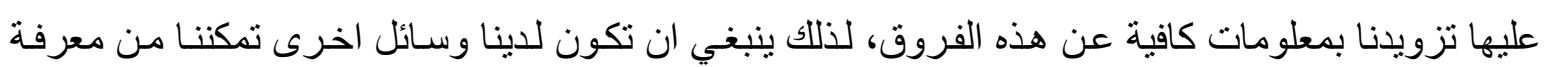

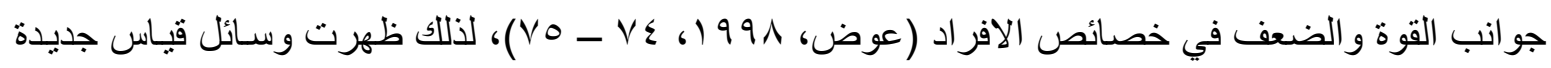
تحاول الكثف عن التنظيم العقلي باكثر دقة، وهي اختبارات القدرات الخاصة، واختبار ات الاستعدادت.

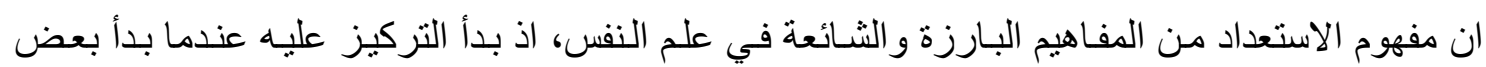
علماء النفس يرون ان الذكاء الانسـاني يتكون من مجموعة من العوامل او القدرات ولا ينحصر في عامل و واحد، وكان من اشهر هم العالم الامريكي (ثيرستون) بينما اعتمد على منهج تحليل العو امل في وصف التنظيم العقلي لدى الافراد. فان اول ما نشأ من نظريات تحليل العو امل هي نظريـة الاستعداد المتعدد ( Aptitude (Multifactor بحد ذاتها نظريـة تفصيلية للذكاء هدفها العـام التمييز بين انو اعـه المختلفة عند الافر اد للاغر اض توجيهيـه تربوية متعددة، وكان اول اختبار من هذا النوع هو في اختبار ات تيرستون، إذ ميز حينها بين انواع متعددة

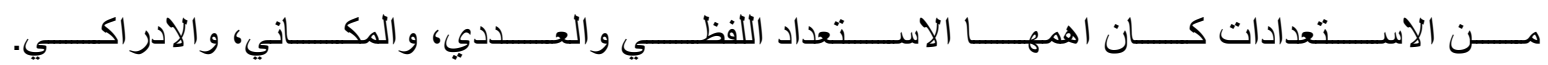

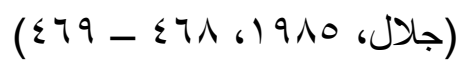
و عدة النظريـات التـي تقوم بدراسـة الفروق الفرديـة وهي (نظريـات الذكاء)، ان الذكاء اهم صـفة مـن

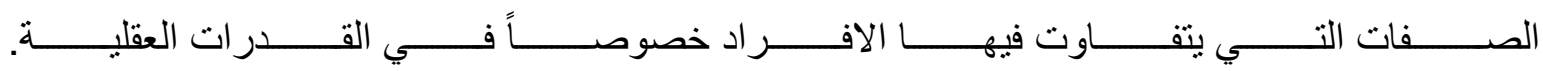

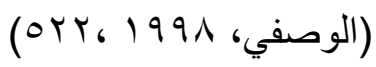


لذا عِد العلماء اختبار ات الذكاء نوعاً من انواع الاختبار ات الاستعداد كل منها يستهف التتبؤ، فالذكاء يقيس قدر ات خاصة : اللغوية، والعددية والمكانية و القدرة على التذكر و التفكير، بينما اختبار ات الاستعدادات

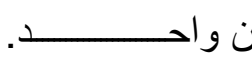
ف القن آ (ب) تق (ะ)

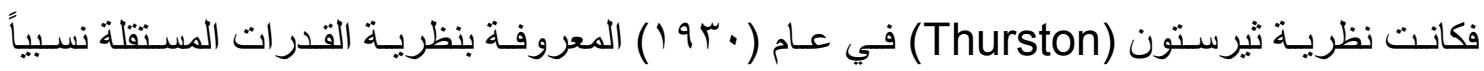
بعضها عن بعض، واعداد اختبار لقياس هذه العوامل يسمى اختبار القدرات العقلية الاولية وتقيس عدداً كبيراً من القدرات في ان واحد، وقد توصل الى هذه النظرية باستخدامه منهج التحليل العاملي الذي وضعه سبيرمان و استخدم انمـاط مختلفة مـن المهمـات الاختباريـة كالاسئلة الدالة على الاستيعاب اللفظي و الحسـاب و التحليل

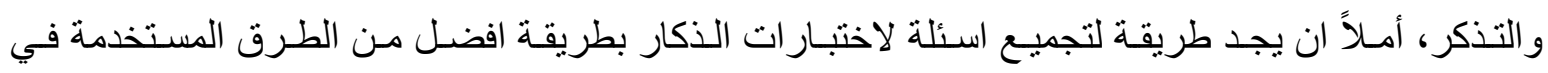

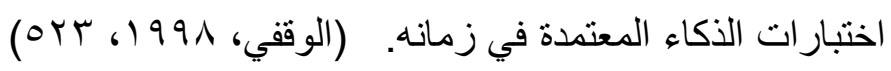
كانت الانطلاقهـ الاولى لار اء ثيرستون و ايمانسه متجهه لاثبـات نظريته في التكوين العقلي بعد رفضـهـ

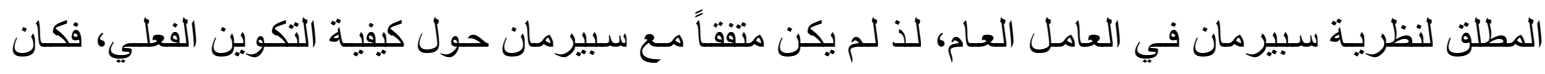
رفضـه للعامل العـام قاطعـاً وكذلك الامـر مـع العو امل الخاصـة لدى سبيرمان، إذ اعتقد ثيرستون ان التنظيم العقلي يتكون من مجموعة من العوامل المستقلة كثيراً او قليلاً مع بعضها، فكان مختلفاً مع سبيرمان حول بناء

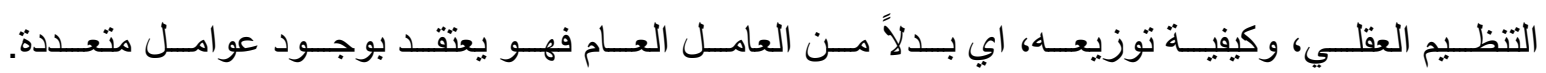

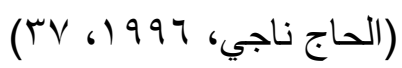

ان اعتماد ثيرستون منهج التحليل العاملي، كان من خلال تطبيقه على عدد من الاختبار ات على عينة من

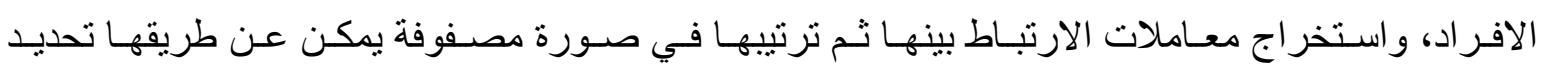
الاختبار ات التي يكون بينها معساملات ارتباط عاليه، ثم تصنيف هذه الاختبار ات في صسورة مجموعـات،

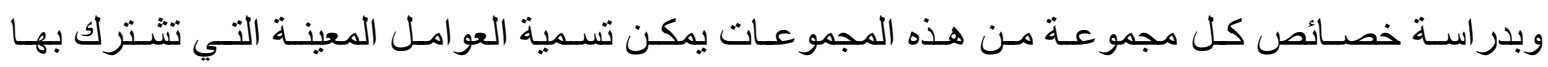
الاختبار ات التي تتضمنها. ولكي تظهر العو امل الاساسية التي يرجع بها الاداء العقلي كان لابد من ان تنوع

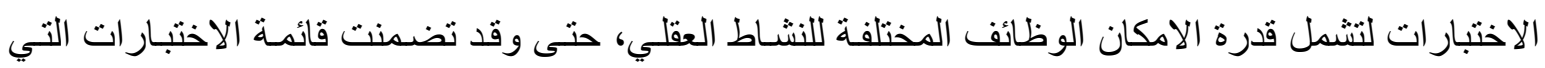

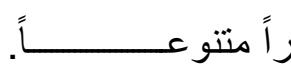

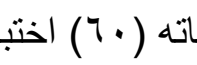
دي دراسـ ي تخدمها ف

(VV، 19VV (محمود) وتحدد نظريـة ثيرستون المعالم الرئيسية للنشـاط العقلي المعرفي في قدرات طائفية اولية تمثل العينـات الاولى للعقل البشري، وتعتمد فكرة القدرات الطائفية الاولية في جوهر ها على تصنيف النشاط العقلي المعرفي لتهي لهي الى انواع منفصلة غير متر ابطة او متداخلة، وبذللك تصبح العلاقة بين ايـة قدرتين من هذه القدرات مسـاوية للصفر، ويتلاشى بذلك التداخل القائم بين مساحتيها، و هكذا يختفي مفهوم الذكاء ليحل محله مفهوم جديد يؤكد

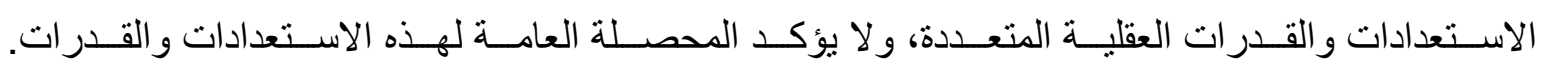

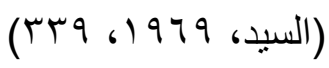
ويقترح ثيرستون تصنيف السلوك في التنظيم العقلي الى اربعة مستويات هي : 
أـ سلوك المحاولة والخطأ الفعلية : وهو السلوك الادنى في المتسويات الاربعة، اذ عن طريق المحاولة

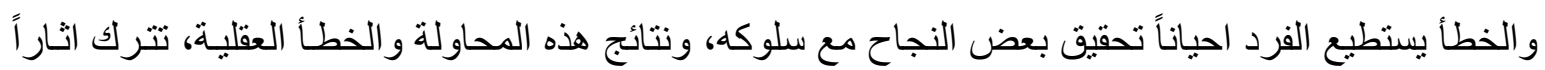
على الفرد و البيئة معاً.

ب- مستوى الذكاء الادر اكي Perceptual : وهو مستوى اعلى نسبياً من المحاولـة والخطأ العقلية،

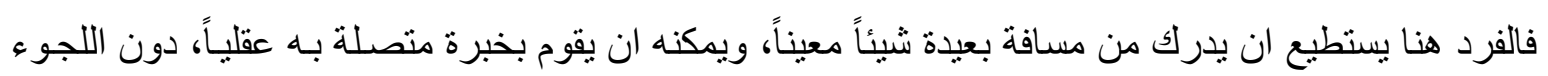
الى المحاولة و الخطأ الفعلية.

تــ مستوى الذكاء الذهني Ideational : او التخيلي، اذ بالتخيل تستطيع ان تتنبأ بـالخبرة دون ان تقابلها مباثرة، و هذا المستوى تستخدمه عندما تكون البدائل اقل قيمـة موقف مـا، فكان كانت البدائل اكتمالاً كان السلوك اكثر ذكاءاً.

ثـ مستوى الذكاء التصوري Conceptual : وهو المستوى الاعلى، وفيه تكون المحاولة والخطأ على شكل تصورات عقلية، والتصور لاى ثيرستون هو السلوك المتوقع غير المنفذ او غير المكتمل. (الثيخ، · 199)

ويرى ثيرستون ان النشاط العقلي عبارة عن مركب عام يتألف من بعض القدرات العقلية بنسب معينة

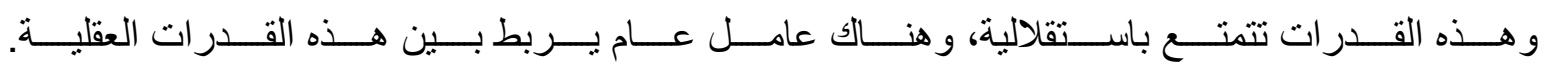

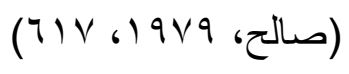
ويشير مفهوم الاستقلالية مع القدرات العقلية الى الاستقلالية النسبية، ابي ان الفرد الذي يتفوق في القدرة

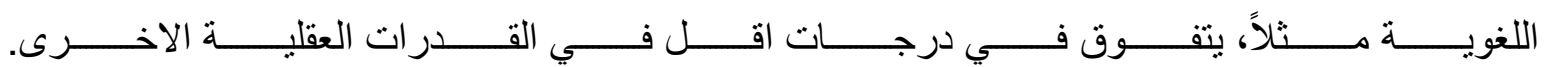

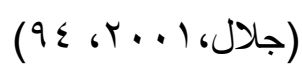
كما يرى ان تفوق الفرد في احدى هذه القدرات لا يعني بالضرورة تفوقه في القدرات الاخرى، فقد تكون للفرد قدرة عالية على ادر الك العلاقات المكانية، ولكنه في الوقت نفسه ضعيف في القدر لـات اللفظية.

(Nunnaly, 1970, 112)

وطبقاً لهذه النظرية فأن القدرات (و العو امل) منفصلة بعضها عن بعض تماماً، اي ان الارتباط بينها يكون صفراً، غير ان الو اقع العملي اثبت ان ذلك ليس صحيحاً، اذ يوجد بين هذه العوامل بعض الارتباطـات التي بـي تُعزى الى عو امل غير العوامل الطائفية الاولى، لذلك فأن طموح ثيرستون لاكتثاف العناصر الاساسية للذكاء

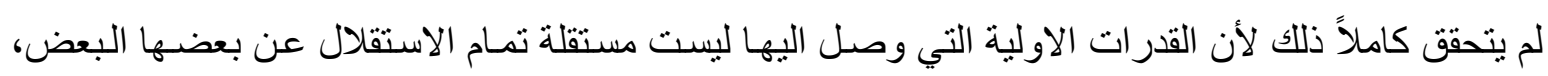
فتمة ارتباطات ضمنية متفاوتة في قوتها تقوم بينها مما يعزز بالتالي وجهة نظر سبيرمان عن وجود عامل لتهل يتخلل هذه القدرات. أضاف ثيرستون وبعض اتباعه الى العوامل الاولية عاملاً عاماً من الدرجة الثانية لكنهم لا يولونه الاهمية

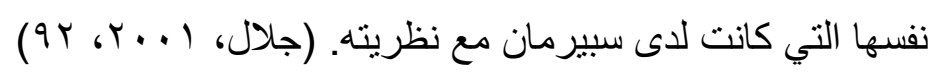
فكان معظم الدراسات التي انجز ها ثيرستون تشير الى وجود ارتباطات موجبة بين الاختبار ات وعو املها مما ادى الى تقليل نسبة الاستقلالية التي كان يشير الى اطلاقها في بـادئ الامر، وهذا مهـا ادى الى استخر اج العامل العام من الدرجة الثانية. 
وكان ثيرستون يفسر العوامل الاولية بأنها تمثنل انواعـاً مختلفة الوسـائط التي تعبر عن النشـاط العقلي كالذاكرة، و الادر الك، والقدرة اللغوية، اما العو امل من الدرجة الثانية فانها تدل على معـالم اكثر مركزيـة واشد

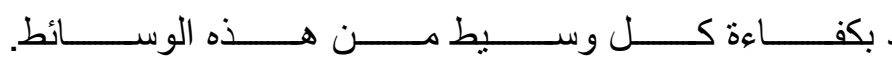
لا تتح

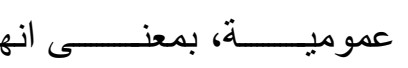

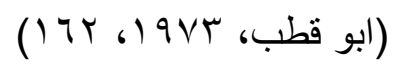
ان هذه القدر ات تتضافر مع بعضها في الانتاج العقلي المعقد، كقدرة الثخص على حل تمرين هندسي او فهم مقال عن الحاسوب، او نظم قصيدة من النثر او تعلم قيادة طائرة، وتتوقف على تضـافر القدرات الاولية، غير ان القدرة العددية، والقدرة على التصور البصري والقدرة على الاستدلال تكون ملزمة لفهم الهندسـة اكثر

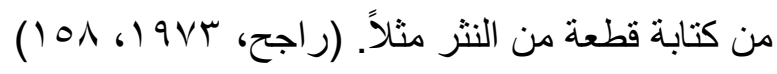
وتوصل ثيرستون الى مجموعة من القدرات العقلية الاولية (Primary Mental Abilities) نتيجة

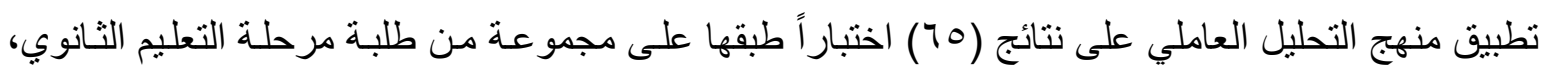
و استطاع تحديد مجموعة من العوامل المستقلة نسبياً بعضـها عن بعض و اعداد اختبار لقياس هذه العو امل يسمى اختبـار القدرات العقلية الاوليـة، وهذه القدرات هي القدرة على الطلاقـة اللفظيـة، والقدرة على الفهم اللغوي، و القدرة العددية، والقدرة المكانية، والسر عة الادر اكية، و القدرة على التذكر، و القدرة على الاستدلال.

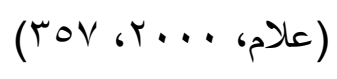

ويمكن تمثيل نظرية ثيرستون حسب المخطط الاتي :

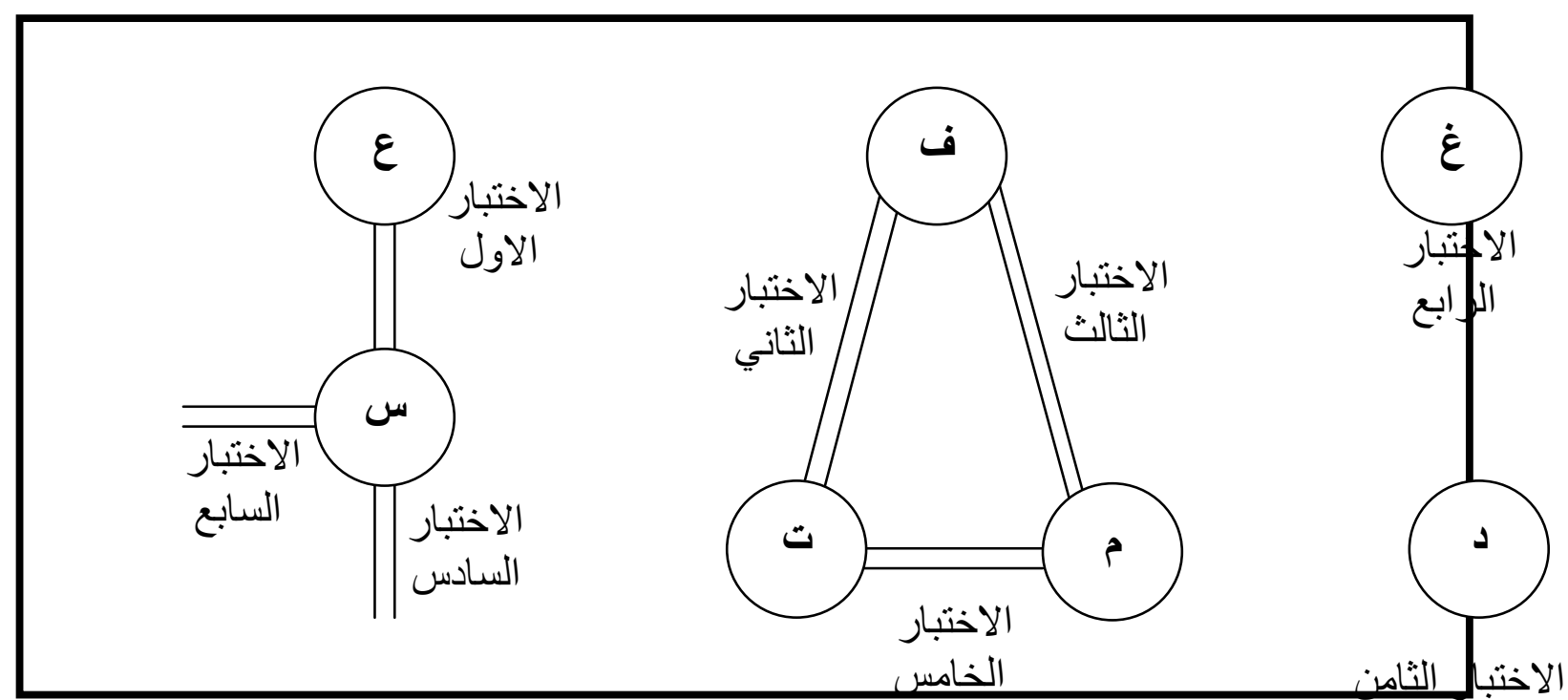

ومن الثكل يتضح ان كل دائرة تمثل عاملاً مستقلاً استقلالاً تاماً عن غيره من العو امل ويقاس بنمط معين من الاختبار ات قد لا تشترك في قياس غيره من العو امل الاخرى حسب الاتي:

- الاختبار الاول : ويقيس بدرجة ضئيلة العامل العددي (ع)، وكذلك عامل الاستدلال اللاستوائي (س).

- الاختبار الثاني : ويقيس بدرجة كبيرة كل من العامل اللفظي (ف) و عامل التذكر (ت).

- - الاختبار الثالث : ويقيس بدرجة اكبر العامل اللفظي وبدرجة اقل العامل المكاني (م).

- - الاختبار الرابع : وهو اختبار لا يصلح إلا لقياس العامل اللغوي (غ). - الاختبار الخامس : ويقيس كل من عامل التذكر و العامل المكاني. 
- - الاختبار السادس والسابع : وهما اختبار ان جيدان لقياس عامل الاستدلال الاستقر ائي.

- - الاختبار الثامن : وهو اختبار نقي لعامل السرعة الادر اكية (د).

ويلاحظ ثيرسون ان القدرات الاربعة الاولى، ترتبط بموضوع الاختبـار او محتو اه، بينمـا تدل القدرات

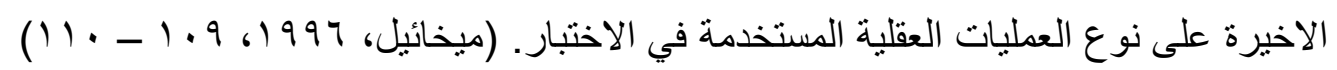
ويرى ثيرسون ان تفوق الفرد في احدى هذه القدرات لا يعني تفوقه في القدرات الاخرى، فقد يكون لدى الدى

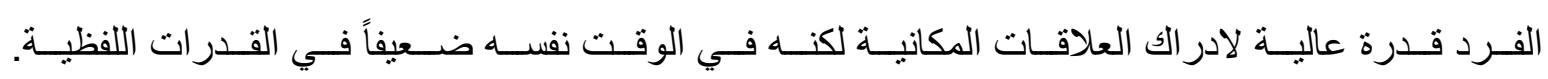

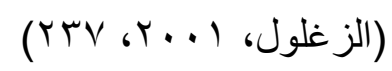

وكان ثيرسون يشير الى افضلية درجات عديدة لوصف القدرات العقليـة بدلاً من اختبار ات الذكاء التي كانت تعتمد على درجة واحدة، وبحسب رسم بروفيل يمثل هذه القدرات لدى الفرد، وهذا البروفيل الذي يكون بئن اساس للتحليل وما يترتب عليه من عمليات التوجيه التعليمي والمهني، وكانت نظرته التطبيقية تسمح باختبار عدد قليل من الاختبار ات التي تمثل القدرة (العامل) خير تمثيل، لاعتمادها في عملية التوجيه، دون الحاجة الى ولى استخدام جميع الاختبار ات التي استخدمت في اشتقاق جميع العوامل وقد نفذ ثيرستون وزوجته هذه الفكرة في اعداد (0) بطاريات اختبار ات لقياس القدرات العقلية الاوليـة في مسنتويات عمريـة مختلفة وتمكن من خلالها من الحصول على بروفيل لعدد من القدرات العقلية المستقلة نسبياً.

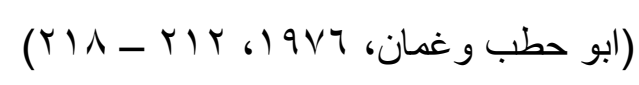

تعد سلسلة اختبار ات (اوتيس لينون) للقدرة العقلية من اختبار ات الذكاء الجمعيـة اللفظية، التي ظهرت

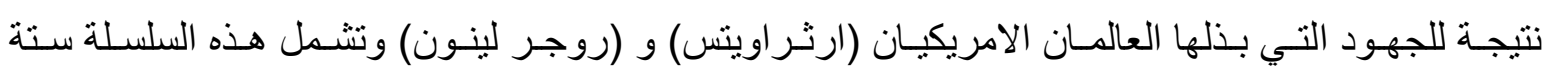

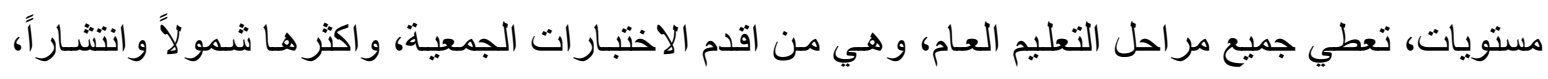
وقد مرت هذه السلسلة بمر احل متعددة من التعديل والتطوير، وتمتد جذور هذه السلسلة الى اطروحة الدكتور اه

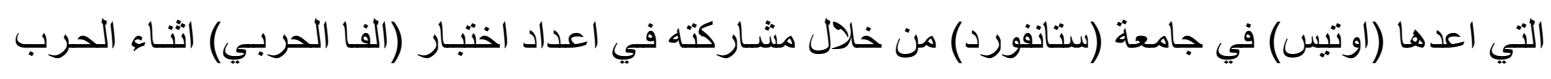
العالمية الاولى و الذي يعد اول اختبار جمعي للذكاء، وقد سمح بأستخدامه بعد الحرب في المدارس و وعلى ألى

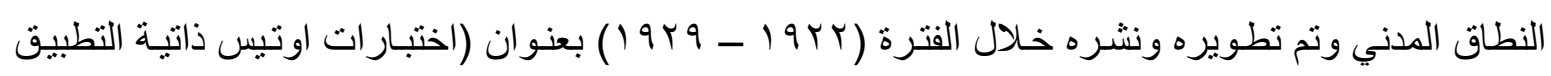
للقدرة العقلية) وقد شملت هذه النتيجة عدداً من التغييرات في تنظيم الفقرات لتسـهيل تطبيقها، وفي منتصف

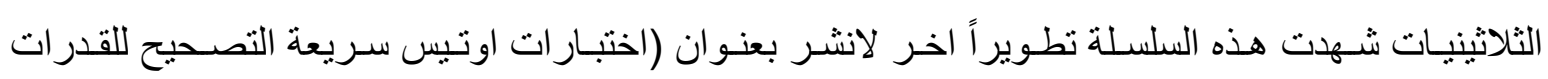

العقلية).

وتضمنت تعديلات في محتوى الفقرات وطريقة التصحيح، وتوفر مزيداً من الدقة والسرعة في التصحيح

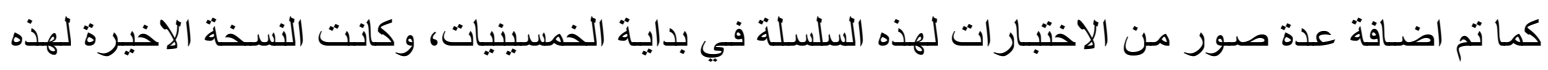
السلسلة اكثر اكتمالاً ونضجاً، فقد استفادت من التعديلات و الدراسات الكثيرة التي اجريت على الاختبـار خلال ما يزيد عن نصف قرن، وظهرت عام (9 9 ( ) بعنوان (سلسلة اختبار ات اوتيس - لينون للقدر ات العقلية)

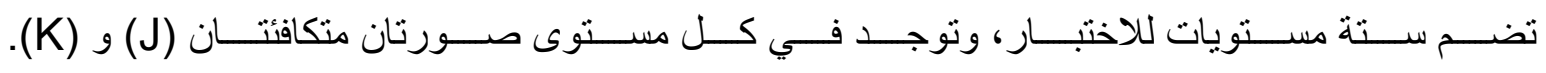

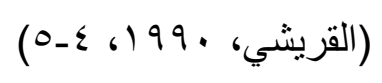

وفيما يأتي وصف موجز لكل مستوى من المستويات التي تتألف منها هذه السلسلة : 
1- المستوى التمهيدي الاول (Primary Level I)

اعد هذا المستوى لقياس القدرة العقلية لدى الطلاب في رياض الاطفال في النصف الثاني من العام

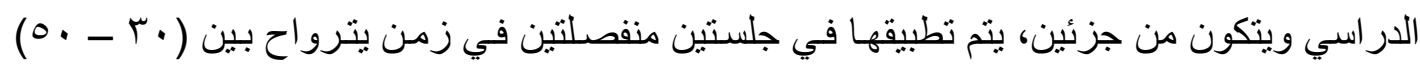
دقيقة تقريباً.

r- المستوى التمهيدي الثاني (Primary Level II)

اعد هذا المستوى لقياس القدرة العقلية لدى طلاب الصف الاول الابتدائي في النصف الاول من العام الدر اسي، ويتم تطبيقه في جلستين منفصلتين، كما ان المحتوى وزمن التطبيق و عدد الفقرات في هذا المستوى مماثل لمحتوى ومن تطبيقه في المستوى التمهيدي الاول وعدد الفقرات في المستويين التمهيدي الاول والثاني (00) فقرة في لكل مستوى.

r- المستوى الابتدائي الاول (Elementary Level I)

هذا المستوى معد لطلاب الصف الاول الابتدائي، في النصف الثناني من العام الدراسي وحتى نهاية

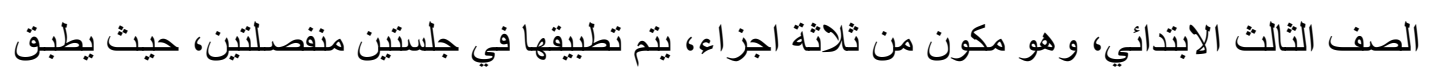

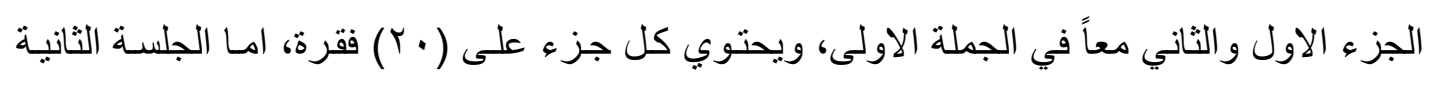
فيطبق فيها الجزء الثالث وعدد فقر اته (0 (1) فقرة، وجميع هذه الفقرات مصسورة وعددها (•^)، و ولا يتطلب الاجابة عليها القدرة على القراءة والكتابة، ويجري التطبيق في زمن يتراوح بين (00 ـ - ؟ ) دقيقة تقريباً وجميع الفقر ات في المستويات الثلاثنة السـابقة فقرات مصورة و لا يتطلب الاجابـة عنها قدرة على الكتابة و القر اعة.

عـ - المستوى الابتدائي الثاني (Elementary Level II)

اعد هذا المستوى للطلاب في الصف الرابع وحتى الصف السـادس الابتدائي، ويتكون هذا الاختبار مــنـ جزء و احد، يطبق في جلسـة واحدة، والزمن المخصص لتطبيقه يتـر اوح بين (0؛ - ـ 0) دقيقة وعدد

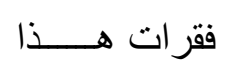
الاختبار ( • (^) فقرة.

0- المستوى المتوسط (Intermediate Level)

و هو معد لقياس القدرات العقلية للى الطلاب من الصف الرابع الى العاشـر، ابي من الصف الاول المتوسط الى الصف الثالث المتوسط، ويتكون هذا الاختبار من جزء و واحد، يطبق في جلسـة واحدة،

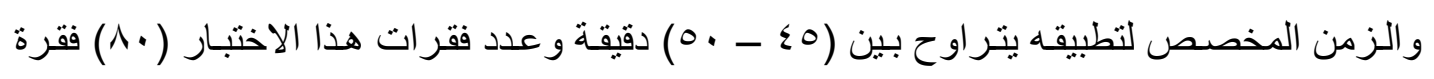
وتمثنل فقرات هـذا الاختبـار العمليـات الاتيـة : الاستيعاب اللفظـي، الاسـتـلال اللفظـي، الاسـتلال الشكلي، الاستدلال الكمي. 7- المستوى المتقدم (Advanced Level) و هذا المستوى معد لقياس القدرات العقلية لدى الطلاب من الصف العاشر وحتى الصف الثاني عثر، اي من الصف الاول الثانوي الى الصف الثالث الثانوي، ويمكن تطبيقه ايضـاً على المر احل التاليـة 
للمرحلة الثانويـة ويتكون هذا الاختبـار من جزء واحد يطبق في جلسـة واحدة والزمن المخصص

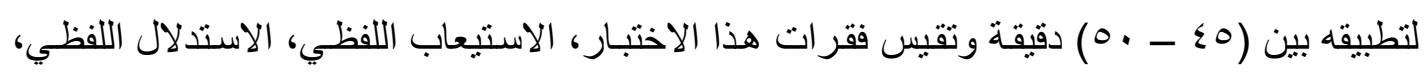

$$
\text { الاستدلال الثكلي، و الاستدلال الكمي. }
$$

و هذه المستويات الثناثة الاخيرة، تسمى المستويات العليا، وجميعها تتكون من ( • (م) فقرة وتستخدم في

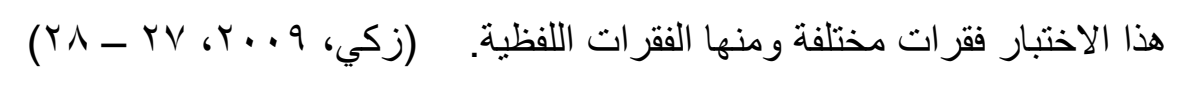

ويمكن تصنيف فقرات الاختبار وفقاً للمجالات الاربعة الاتية :

1- الاستيعاب اللفظي (Verbal comprehension) :

ويشمل على (التعاريف المنرادفة، العكوس، واكمل الجمل، و الجمل الغامضة).

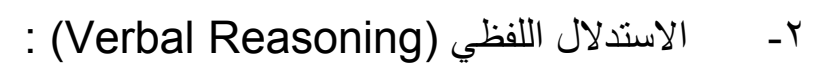

ويشــل على (تركيب الكلمـات حسـب الاحـرف، و القياسـات اللفظبـة، المـؤهلات اللفظيـة، والاسـتلالات و الاختبار ات اللفظية).

r- م : الاستدلال الثكلي (Figural Reasoning) :

ويشمل على (القياسات الثكلية، وسلاسل الاكمال، ونماذج التركيب)

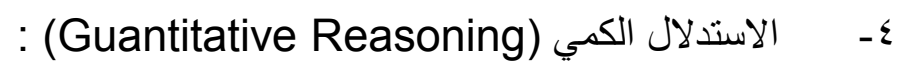

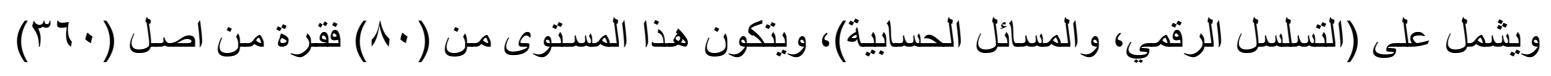

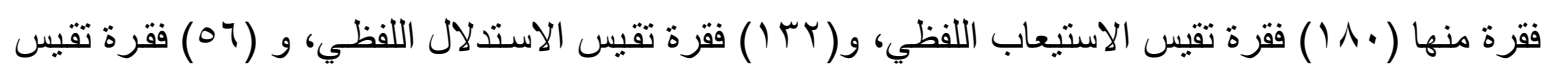

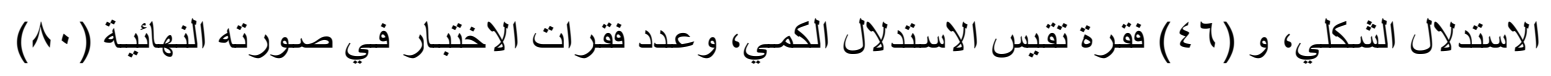
فقرة موزعة على النحو التالي : الاسنول

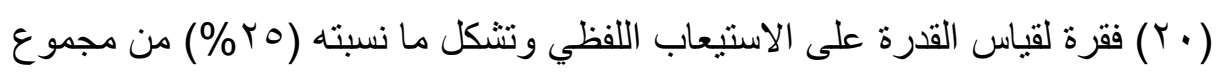
فقرات الاختبار . (rץ) فقرة لقياس الاستدلال اللفظي، وتشكل ما نسبته ( • ؛\%) من مجموع فقرات الاختبار .

(10) فقرة لقياس الاستدلال الثكلي، وتشكل ما نسبته ( 9 (1\%) من مجموع فقرات الاختبار.

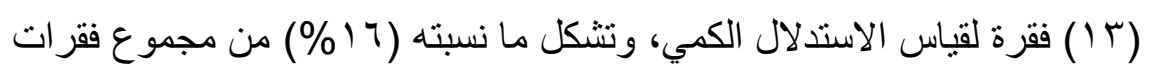
الاختبار.

(Otis \& Lennon, 1969, 9-11)

$$
\begin{aligned}
& \text { ثقانياً // دراسات سابقة : }
\end{aligned}
$$

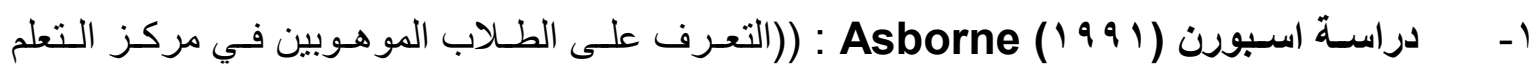

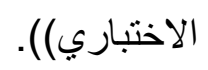


حيث تم استخدام اختبار (اوتيس - لينون) للتعرف على المو هوبين وكذلك القدرات الابداعية والرياضية فضلاً عن حنَ تقارير المدرسين للتعرف على الطلاب الموهوبين، وتكوين عينة الدراسة من (بوه) طالباً من الصف الحادي

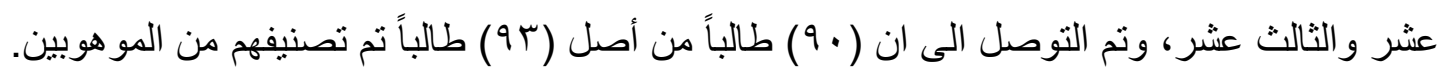

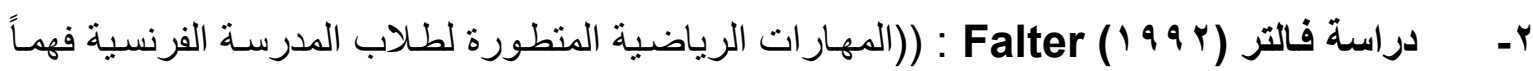
لارجات ذكاء عالية)). حيث طبقت الدراسة على (YVY) طالباً في الصف الرابع، (YVO) طالباً في الصف السـابع، وقد طبق عليهم اختبـار رياضيات واختبـار (اوتيس - لينون) كمـا تم اختبـار هم من البرنـامج الانكليزي الفرنسي واسفرت

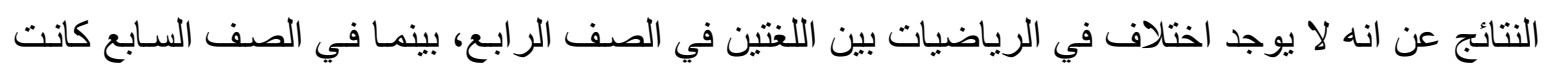

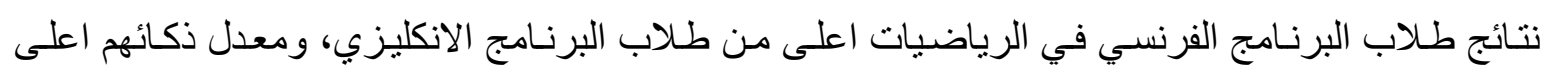
بالمقارنة مع طلاب العاديين.

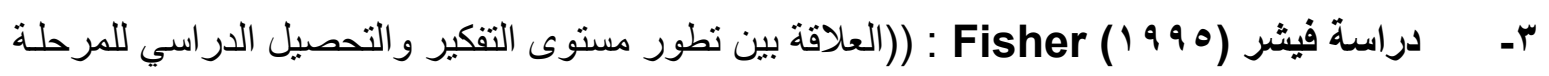
المتوسطة)). وصدقت الدراسة الى معرفة العلاقة بين الاختبارات اللفظية وغير اللفظية، وقد تم استخدام اختبار (اوتيس لينون) لاشتماله على النوعين حيث تم تطبيق الاختبار على (09 (1) طالباً من مدينة اوهايو.

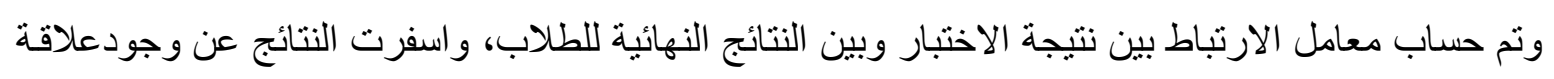
ايجابية بينهما، اي بين تطور مستوى التفكير والحصول على درجات مرتفعة في التحصيل الدراسي.

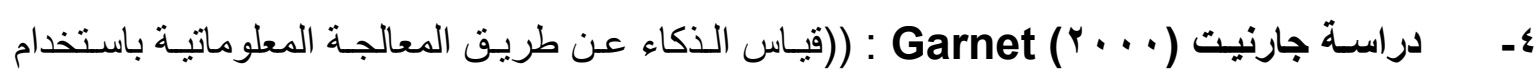
الضبط الزمني)) حيث استخدم برنامج كمبيوتر لقياس الارتباط بين نسبة الذكاء و الضبط الزمني، وقد فئدم البرنامج كعينة فضاء وقدم الى ( T Y ) طالباً في الصف الر ابع و الخامس و السادس، حيث تمت مقارنـة النتائج بنتائج (اوتيس - لينون)، وقد اسفرت النتائج عن ان الاطفال الذين حققو انتائج عالية في الضبط الزمني كانت

$$
\text { نتائجهم عالية في اختبار (اوتيس - لينون). }
$$

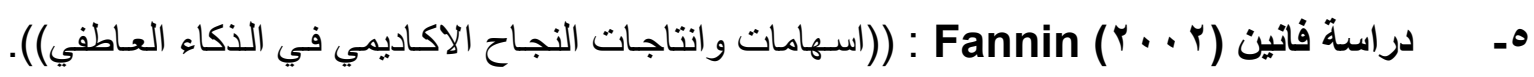

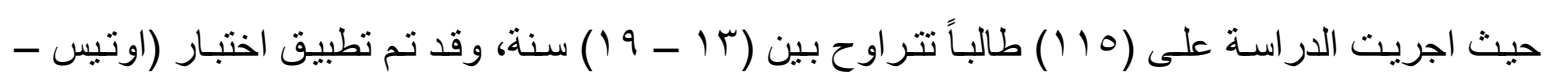
لينون) عليهم، ونم التوصل الى انه توجد علاقة ايجابية بين الذكاء العاطفي والتحصيل الدراسي.

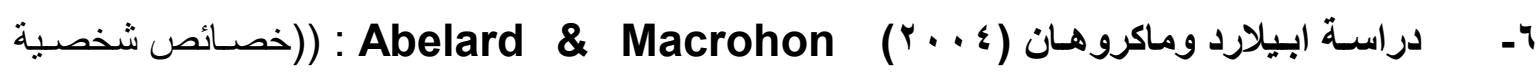
الطلاب كمحددات للنجاح في أحد مقررات الكلية الطبية)). و التي صدقت الى فحص العلاقة بين خصـائص شخصية الطلاب الضرورية للالتحساق بالكلية والقدرة على في التنبؤ بالاداء المرتفع في المنهج و المقررات الطبية، حيث شملت الدراسة جميع الطلاب الر اغبين في الالتحساق بكلية زامبواني الطبيـة بالفلبين، وقد تم تطبيق عدة اختبار ات لقياس الثخصية، واستخدام برنـامج التفاضل

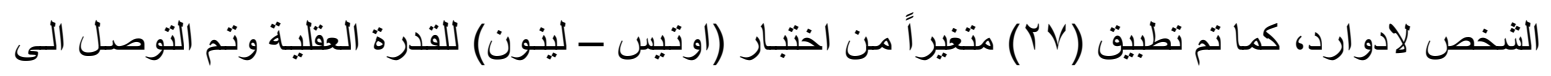
عدم وجود علاقة بين خصائص الثخصية والتحصيل المرتفع في المنهج الدراسي. 


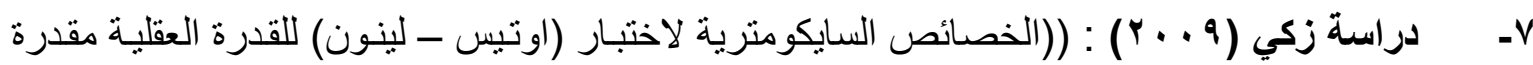
وفق القياس الكلاسيكي ونموذج ر اش لدى طلبة المرحلة المتوسطة عن خطة صبا التعليمية)). وصدقت القياس الكلاسيكي، و التعرف على الخصائص السايكومترية لاختبار (اوتيس - لينون) للقدرة العقلية وفق نموذج راش، وتم اختيار عينة الدراسة بطريقة عشوائية من جميع طلاب الصفوف المرحلة المتوسطة

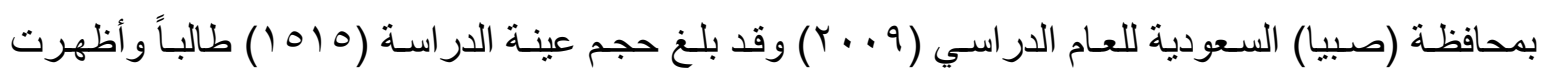
النتائج في مستوى قدرة الطالب وتفسير مستوى قدرته بالنسبة لأقر انه عن كل صف در اسي.

\section{ثالثَ // موثشرات ودلالات الدراسات السابقة :}

1 ـ تحديد هدف الدراسة الحالية، بما يتناسب مع اداة البحث المستخدمة وهذا مـاورد من خـلال الدراسـات

السابقة.

r- تنوع العينة من در اسة الى اخرى، وهذا يسـاعد الباحثان في ان يختار المستوى المناسب من الاداة للعينة الحالية.

r- استخدمت جمل الدراسات السابقة اختبار (اوتيس - لينون) وكما هو الحال في الدراسة الحالية، وهذا يؤكد فاعلية الاداة. ع- تحديد الوسائل الاحصائية الملائمة لأحتساب النتائج.

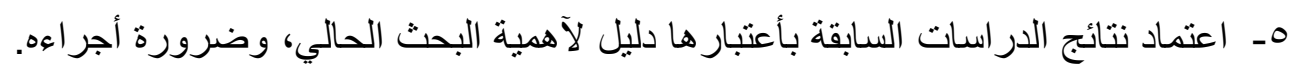

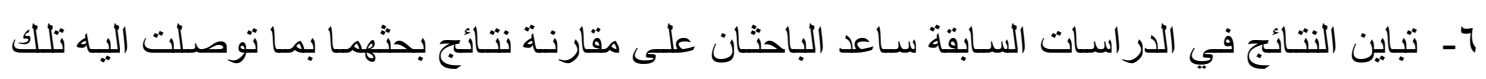
الدر اسات.

\section{الفمل الثالث : اجراكات البمث}

يتضمن هذا الفصل وصفاً لاجر اءات التي قام بها الباحثان من حيث تحديد المنهج الملائم ومجتمع البحث، وخطوات تحديد اختيار عينته و الاداة المعتمدة والوسائل الاحصائية المناسبة وعلى النحو الاتي :

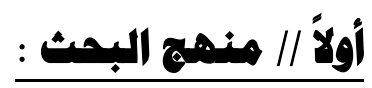
اعتمد الباحثان في هذا البحث، المنهج الوصفي وذللك لملائمتهـ لطبيعة اهداف بحقها كونهـ من الدراسـات التي تهتم بالكثف عن خصائص المجتمع ونوع العلاقة بين متغير اته والتعبير عنها بصورة كمية تصف مدى امتلاك ذلك المجتمع للسمات المر اد در استها.

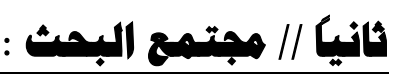
استعان الباحثان بقسم التخطيط التربوي لمعرفة اعداد المدارس المتوسطة و الثانويـة النهاريـة على وجـهـ الحصر و اعداد الطلبة في تلك المدارس ولكعلا الجنسين، وذلك للوصـول الى تحديد واضـح ودقيق لمجتمع البحث واختبار العينة المناسبة له. وفيما يلي عرض مكونات مجتمع البحث :- 
1 - مجتمع المدارس : جاء عدد المدارس المتوسطة و الثانوية التابعة الى قسم تربية الهاشـية بو اقع (Y^)

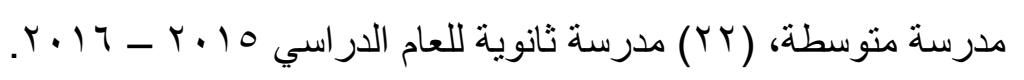

r- مجتمع الطلبة : بلـغ عدد الطلبة (ذكور، انـاث) في عموم المدارس المتوسطة و الثنانويـة التابعـة الى لى

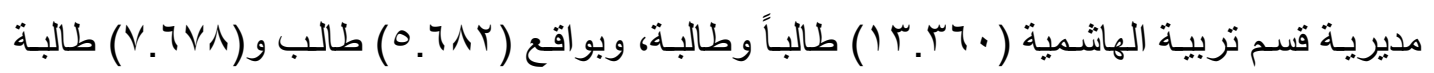
موز عين على المدارس الحكومية للار اسة النهارية.

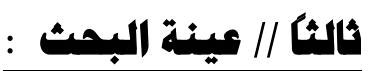

تم تحديد العينة وفقاً للمعادلة الاحصائية الخاصة بتحديد مجموع العينات بالصورة الرياضية التالية :-

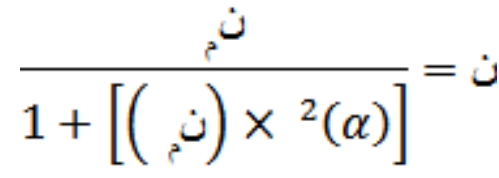

$$
\begin{aligned}
& \text { حيث ان : } \\
& \text { ن = حجم العينة } \\
& \text { نم = حجم المجتمع الاصلي } \\
& \text { o }
\end{aligned}
$$

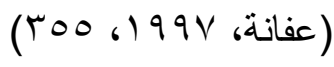

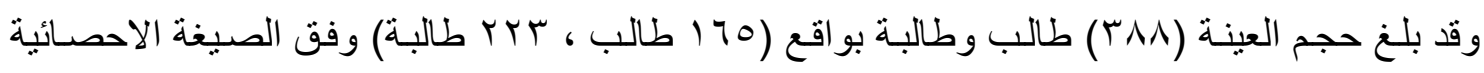
قباساً بعدد الطلبة الكلي في مجنمع البحث، ونسبة هم المتعدة.

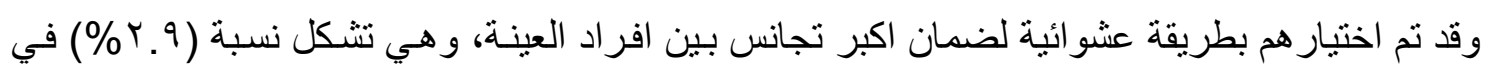

$$
\text { افراد المجتمع الاصلي. }
$$

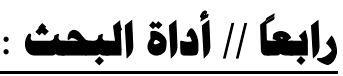

قام الباحثان باختيار (· • فقرة من القسم الخامس (المستوى المتوسط) و الخاصة بقياس الاستدلال الكمي من اختبار (اونيس - لينون) ضمن المستوى المتقدم الذي يقيس الاستدلال الكمي و عدد فقر اته (·؟) فقرة من

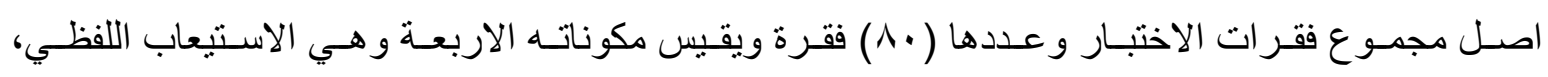
و الاستدلال اللفظي والاستدلال الكمي والاستدلال الثكلي.

\section{خامسكا // الفصائص السايكومنزية للاداة :}

ا - صدق الاختبار : يعد الصدق من الخصـائص المهمة في اعداد الاختبار للحكم على مدى صـلاحيته وقدرته على قياس الظاهرة التي ير اد دراستها، ومن اكثر المؤثرات السيكومثرية اهمية في اعداد الاختبار.

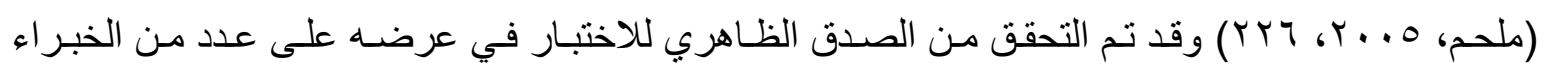

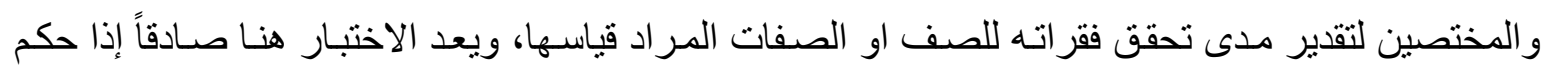

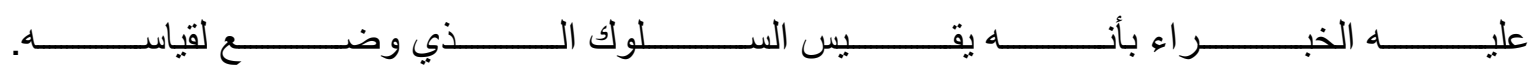


(الزيود و هثـام، بـ ( ) وقد تم عرض فقرات الاختبـار على مجموعة من الخبراء و المختصين في التربيـة

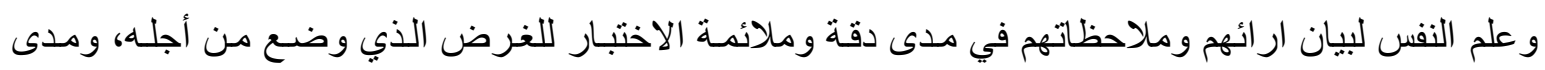

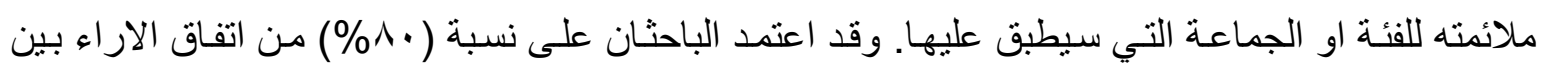
المحكمين على صلاحية الفقرة كحد ادنى لقبول تللك الفقرة، حيث اشار (Bloom) الى ان هذه النسبة متو افقة

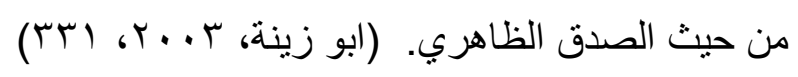
r- الثبات : للاعتماد على اداة البحث يجب ان تتصف بالثبات، وهذه الصفة تتحقق عندما تعطي النتائج نفسها (تقريباً) في كل مرة يطبق فيها المقياس على نفس المجموعة وفي نفس الظروف. (ابو عبدة، م ... r،

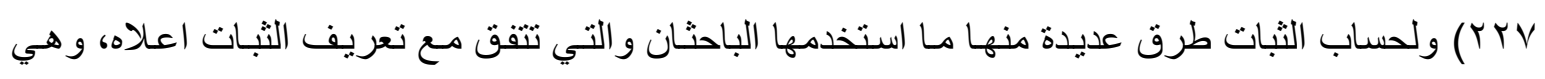

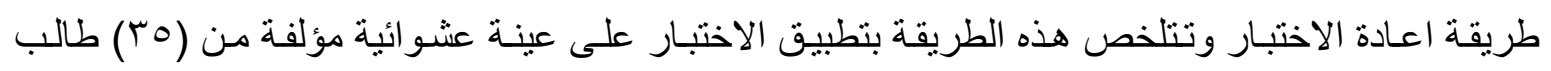
وطالبة، وتمت اعادة التطبيق واستعمل الباحثان معامل ارتباط بيرسون، حيث ظهر معامل الارتباط (rیی. • )

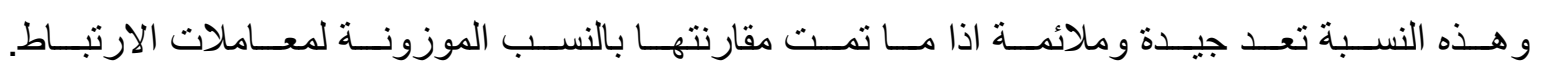

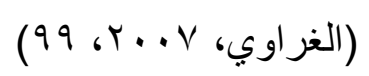

r- القوة التميزية للققرة : تعني امكانية كل فقرة من الفقرات ضمن الاداة المستخدمة على التمييز بين

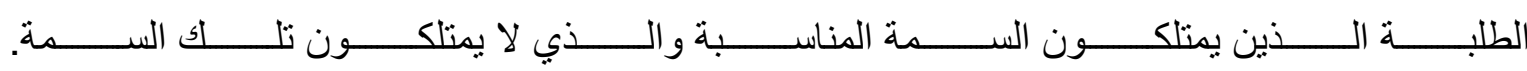

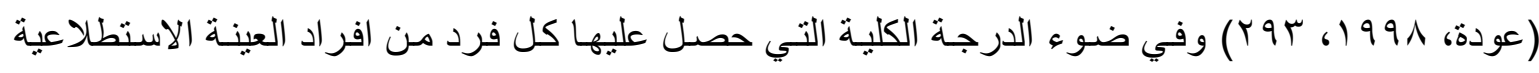

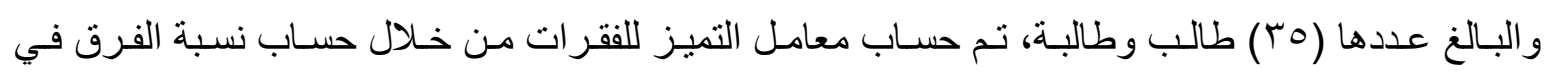
الاجابات الصحيحة في المجموعة العليا والدنيا الى عدد الافراد وفي المجمو عتين ووجد انها تتر اوح بين

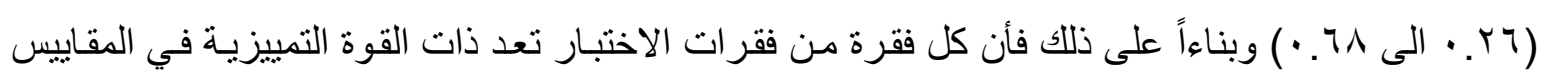
(Ebel, 1972, 22) والاختبار ات.

سادسك // الوساثل الاعصائية : استخدم الباحثان الوسائل الاحصائية التالية التي تتناسب مع اهداف البحث : 1- الاختبار التائي لعينة واحدة : للتأكد من مستويات عينة البحث في متغير البحث من خلال دلالة الفرق

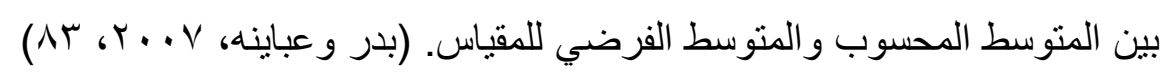
r- الاختبار التائي لعينتين مستقلتين : لاستخر اج دلالة الفرق بين متوسطي الذكور و الانات في درجات القياس. r- - معامل الارتباط بيترسون لأحتساب ثبات المقياس في التطبيقين.

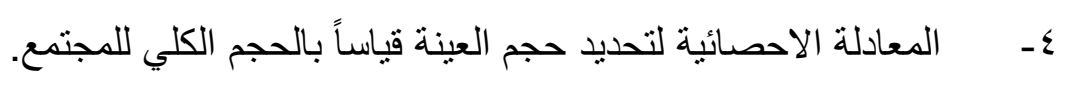

\section{النمل الرابع : نتائه البمث}

يتضمن الفصل الحالي عرضاً لنتائج البحث التي تم التوصل اليها في ضوء التحلبلات الاحصـائية وفقاً لفرضيات البحث واهدافه المحدده، ومناقثنة وتفسير تللك النتائج في ضل الادبيات والدر اسـة السـابقة، مـع بيـان أهم الاستتناجات و التوصيات وتقديم المقترحات الممكنة حول بحوث مستقبلية ذات علاقة وصله لاستكمال 


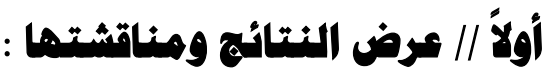

1- الههف الاول : الكثف عن درجة الاستدلال الكمي لطلبة المرحلة المتوسطة :

وقد تم التحقق من الهدف اعلاه في ضدو الفرضية الصفرية القائلة (لايوجد فرق ذو دلالنة إحصـائية عند مسـتوى دلالـة (0 . . •) بـين المتوسط الفرضي و المتوسط الحسـابي لدرجات طلبـة عينـة البحث في إختبـار

$$
\text { . (اوتيس - لينون) (الئ) }
$$

ثم تم حساب المتوسط الفرضي و المتوسط الحسابي و الانحر اف المعياري لدرجات الطلبة، وبأستخدام الاختبار

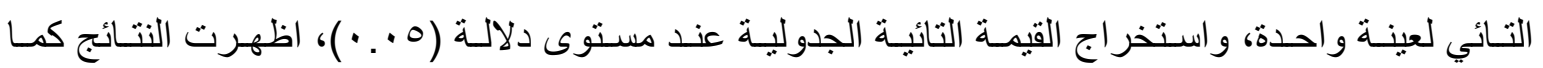

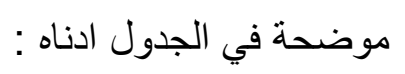

\begin{tabular}{|c|c|c|c|c|c|}
\hline \multirow{2}{*}{ مستوى دلالة } & \multicolumn{2}{|c|}{ قيمة تاء } & \multirow{2}{*}{ الاتحراف المعياري } & \multirow{2}{*}{ المتوسطات } & \multirow{2}{*}{ المجموعة } \\
\hline & جدولية & المحسوية & & & \\
\hline \multirow{2}{*}{ دالة } & \multirow{2}{*}{1.91} & \multirow{2}{*}{19.1 .1} & $\varepsilon . V Y q$ & $1 \& . \wedge \wedge$ & عموم العينة \\
\hline & & & صفر & 1. & المجتمع \\
\hline
\end{tabular}

جدول ( () القيمة التانية للالة الفرق بين المتوسط الفرضي والمتوسط الحسابي للارجات عينة البحث في إختبار (اوتيس - لينون) للاستلال الكمي

يتضح من الجدول اعلاه ان قيمة تاء المحسوبة والبالغة (1 • (9 1 ) هي اكبر من قيمة تاء الجدولية البالغة

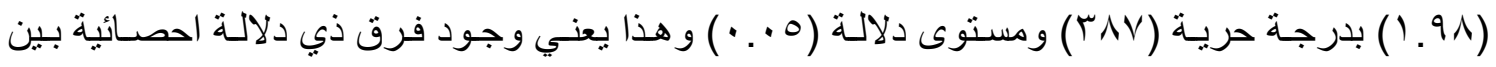

متوسط اداء الطلبة على الاختبار و المتوسط الفرضي، ولصالح عينة البحث. وبذلك ترفض الفرضية الصفرية، وتقبل الفرضية البديلة حيث انـه ((توجد فروق ذات دلالـة احصـائية عند مستوى دلالة ه . . • بين متوسط درجات افر اد العينة والمتوسط الفرضي)).

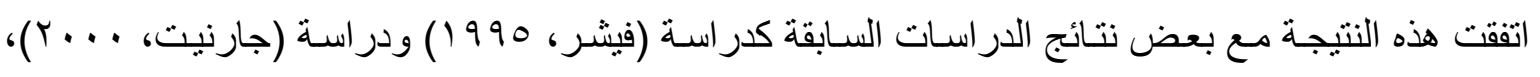
ودراسة (زكي، 9 . . r) التي يبين ان افراد العينة اظهرت نتائج عالية في اختبار (اوتيس - لينون) r- الهـف الثاني : معرفة الفرق بين الاستدلال الكمي بين (الذكور ـ الاناث) لطلبة المرحلة المتوسطة. وقد تم التحقق من الهدف اعلاه في ضدوء الفرضية الصفرية القائلة (لايوجد فرق ذو دلالـة احصـائية عند مستوى دلالة ه . • بين متوسط درجات طلبة عينة البحث في اختبار (اوتيس - لينون) يعزى لمتغير الجنس لغـرض التعـرف على الفـروق بـين الاداء للـذكور والانـاث الحسابية و الانحر افات المعيارية لارجات طلبة عينة البحث للاكور والاناث، واستخدام الاختبار التائي لعينتين مستقلتين كوسيلة احصائية لمعرفة دلالة الفروق بين الادائين على اختبار الاستدلال الكمي عند مستوى دلالة

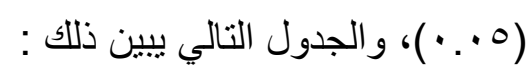

\begin{tabular}{|c|c|c|c|c|c|}
\hline \multirow{2}{*}{ مستوى الدلالة } & \multicolumn{2}{|c|}{ قيمة تاء } & \multirow{2}{*}{ الانحرافياري } & \multirow{2}{*}{ الوسط الحسابي } & \multirow{2}{*}{ العينة } \\
\hline & جدولية & محسوبة & & & \\
\hline غير دالة & 1.91 &. $.1 \mathrm{~V}$ & $\varepsilon . V 0 \leqslant$ & 15.079 & ذكور \\
\hline
\end{tabular}

جدول (ب) القيمة التائية لالالة الفرق بين متوسطي درجات الذكور والاناث في إختبار (اوتيس - لينون) للاستلال الكمي عند مستوى

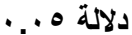




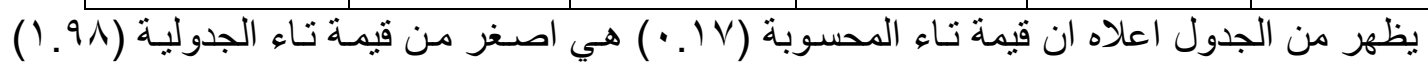

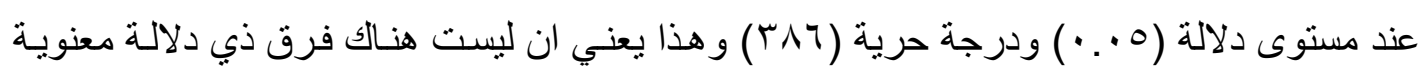

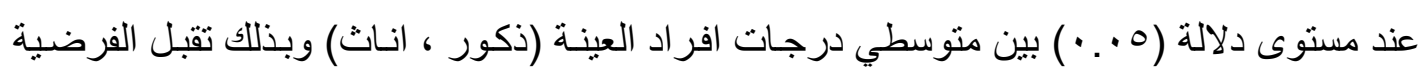
الصفرية. وقد أتفقت هذه النتيجـة مـع مـا توصلت اليـه بعض الدر اسـات السـابقة كدر اسـة (ابيلارد

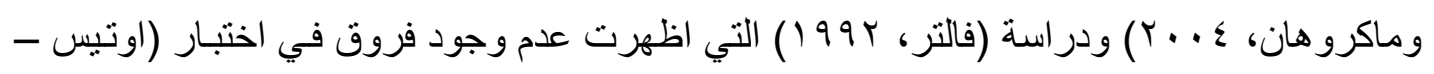
لينون) بين مجمو عات البحث التي طبق عليها.

نجد من خـلال العرض المتقدم للنتائج ان افر اد عينـة البحث يمتلكون القدرة على الاستدلال الكمي مـع الاحتفاظ بالمستوى نفسه اذا ما تمت المقارنة بين اداء الذكور و الاناث، وقد يعود ذلك الى واحد او اكثر من

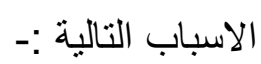

ا - قد تكون الموضوعات الرياضية بالمناهج الجديدة تقدم للطلاب بأسلوب غير تقليدي ممـا يسـاعد على تنمية التفكير الاستدلالي لديهم. r- طبيعة الطر ائق التدريسية الثائعة لدى المدرسين هي المناقثنة والاستجو اب ولعل ذللك ير افقه تثـيع وتعزيز الاجابـات الصحيحة مهـا يولا فكر تربوي وتسلسل منطقي في تلقي المعلومـة وهذا مـا يعزز الفهم الاستقر ائي للمادة. r- ادراك المدرسين لطبيعة التفكير المنطقي والدور الذي يلعبـه في تعلم العلوم، وبالتالي اتباع خطواته في عرض المادة الدراسية او عند حل المسائل والتمرينات مما يساعد على تتمية الفكر المجرد لدى الطلبة.

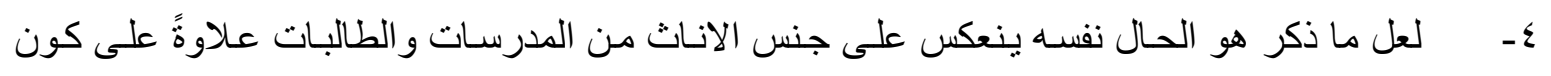

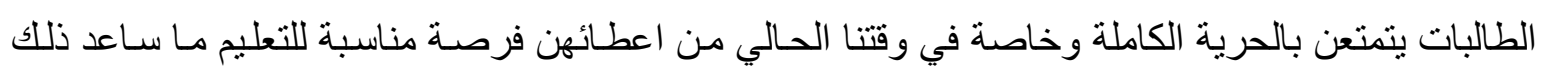
على اختفاء اثر الفرق في الاستدلال الكمي بين الذكور و الاناث.

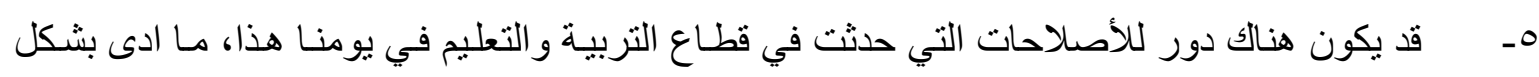
عام الى رفع مستويات الطلبة وتنشيط تفكير هم.

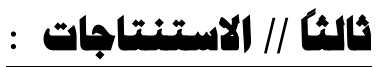

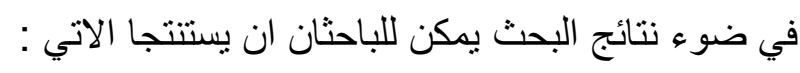
ا - ارتفاع مستوى الاستدلال الكمي لدى طلبة المرحلة المتوسطة. r- الاتوجد فروق في الاستدلال الكمي بين الذكور والاناث.

\section{رابعك // التوصيات :}

في الموء النتائج التي اسفر عنها البحث الحالي، يمكن التوصل الى التوصيات التالية :-

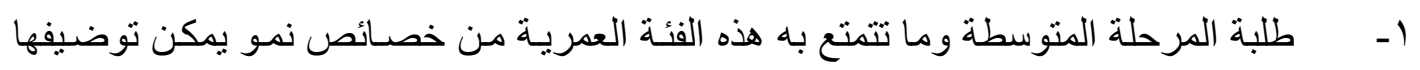
في تنمية انماط مختلفة من التفكير العلمي و على مقدمتها التفكير الرياضي. 
r- المتسوى الجيد من الاستدلال الكمي لاى هذه العينة يمكن ان ينعكس بثكل ايجابي في رفع قابليات الطلبة العلمية في شتى المجالات.

r- العمل على ان تكون هذه المرحلة (المتوسطة) هي بداية الانطلاقة لصناعة جيل متعلم يكون بحد ذاته عنصر للتغيير الايجابي في المجنمع.

ع- - العمل على توفير بعض الامكانيات العلميـة كأقامـة دورات تدريبية مجانيـة لطلبـة المرحلة المتوسطة لتنمية قدر اتهم و اساليب التفكير السليمة لديهم. 0ـ العمل على تطبيق اختبار ات علمية وبصورة دوريـة على هذه المرحلة الدراسية وبأثنر اف من الجهات المختصة لأبر از قابليات وامكانيات افر ادها و اعطائهم رعاية وتوجيه علمي مميز ، لمـا تشكله هذه المرحلة الدر اسية في ارض خصبة للبحث و التجريب و العلمي. خامسط // الاقترحات : استكمالاً للبحث الحالي، يتقرح الباحثان اجر اء الدراسات التالية :ع - الاستدلال الكمي في كتب رياضيات المرحلة المتوسطة. 0ـ الاستدلال الكمي في كتب الفيزياء للمرحلة المتوسطة. T- اثر بعض الاستر اتيجيات التدريسية في تتمية الاستدلال الكمي لاى الطلبة.. V- - بناء برنامج تدريسي للمدرسين في ضوء الاستر اتيجيات المعرفية لتنمية الاستدلال الكمي و اثره في تحصيل طلابهم وتفكير هم الاستدلالي ᄉ- إجر اء در اسة مماتلة في مر احل در اسية اخرى (ابتدائية - ثنانوية - جامعية).

المسادر العربية

1 - تورندايك، روبرت و هجين، اليز ابيث، 1919 : : القياس و التقويم في علع النفس والتربية، الاردن، مركز الثباب الاردني. r- جلال، سعد، 1910 : المرجع في علم النفس، طع، دار المعارف، القاهرة.

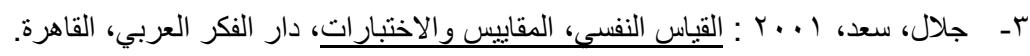

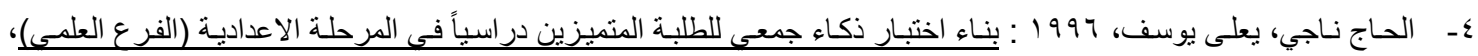

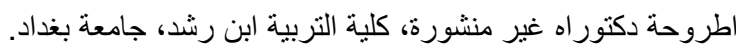

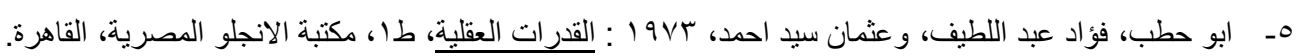

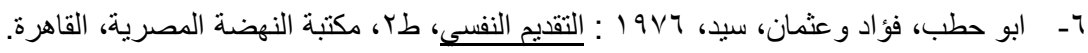

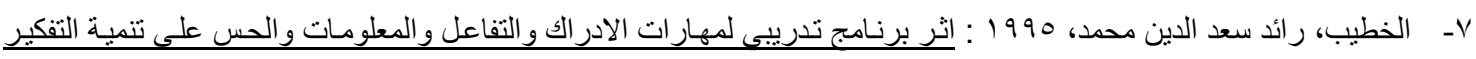
الابداعى لدى طلبة الصف التاسع الاساسى في عينة اردنية، رسالة ماجستير غير منشورة، كلية الدراسات العليا، الجامعة الاردنية.

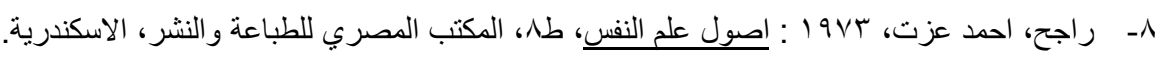

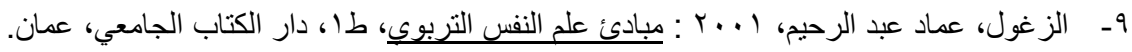

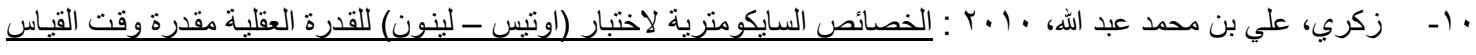
الكلاسيكى ونموذج راش للدى طلبة المرحلـة المتوسطة محافظة صيبا التعليمية، اطروحسة دكتور اه غير منشورة، كلية التربيـة، جامعة ام القرى، مكة المكرمة.

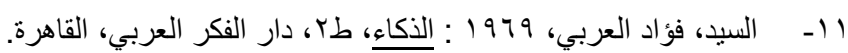
r ا- الطريري، عبد الرحمن سليمان، 1997 : الخصـائص السـيكومترية لاختبار الذكاء الاعدادي باستخدام نموذج راش، دراسيات نفسية، المجلد (7) ، العدد (ع ). 


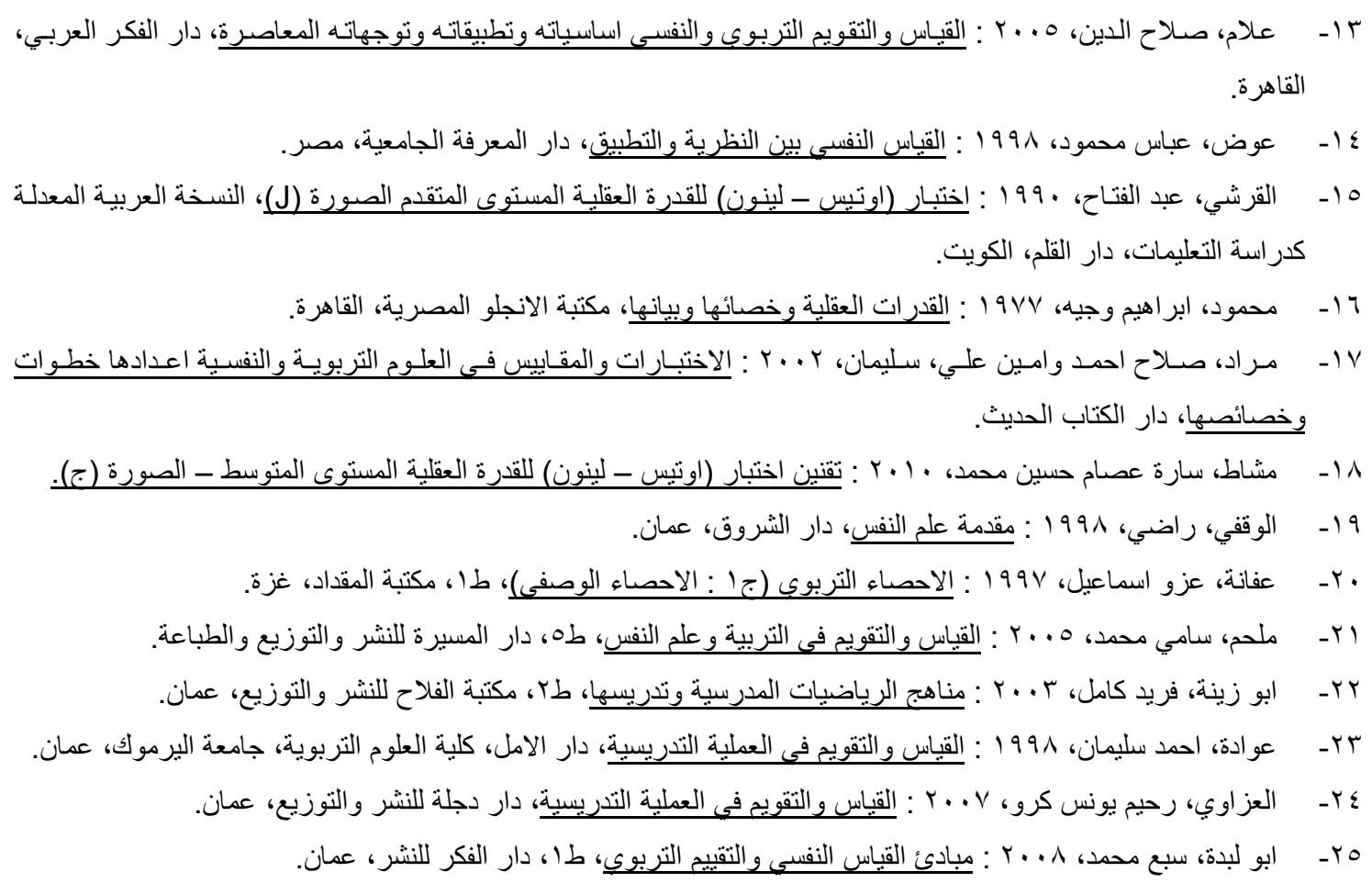

1- Abelardoc, Mocrohou Jr., 2004 : Students characteristics that determine success in an Innovative medical education curriculm online, available : http://www.adu.ph//medschool/v2/reapearch.

2- $\quad$ Aivert, L. G., 1999 : A dependence on technology and algorithms or lack of number sense, teaching children Mathematic, Vol. 6, No.1.

3- $\quad$ Edward, A. J., 1971 ; Individual mental testing part history and theories, International text book.

4- Fatter, pat; Persinger, M. A., 1992 : Improved arithmetic skills of French immersion grade school students are confounded by higher intelligence, Email : (ovidonline@ovide.com)(ovidcitations), perceptual and motor skills, US.

5- $\quad$ Fisher, Janis L., 1995 : Relationship of intelligence quotients to academic achievement in the elementary, (ERIC Document).

6- Vacc, N, N, 1995 : Gaining number sense through a restructured Hundreds chart, Teaching Exceptional children, Vol. 28, No. 1. 